NBER WORKING PAPER SERIES

\title{
USING VIGNETTES TO IMPROVE UNDERSTANDING OF SOCIAL SECURITY AND ANNUITIES
}

\author{
Anya Samek \\ Arie Kapteyn \\ Andre Gray \\ Working Paper 26176 \\ http://www.nber.org/papers/w26176 \\ NATIONAL BUREAU OF ECONOMIC RESEARCH \\ 1050 Massachusetts Avenue \\ Cambridge, MA 02138 \\ August 2019
}

This research was partly supported by a grant from the U.S. Social Security Administration (SSA) as part of the Retirement Research Consortium (RRC). This research was also partly supported by a pilot project as part of a Roybal grant awarded to the University of Southern California, entitled "Roybal Center for Health Decision Making and Financial Independence in Old Age" (5P30AG024962-12). The project described in this paper relies partly on data from surveys administered by the Understanding America Study (UAS) which is maintained by the Center for Economic and Social Research (CESR) at the University of Southern California. The opinions and conclusions expressed herein are solely those of the authors and do not represent the opinions or policy of any institution with which the authors are affiliated nor of the SSA, any agency of the Federal Government, the University of Michigan Retirement Research Center (MRRC), the National Bureau of Economic Research, USC, CESR or the UAS.

NBER working papers are circulated for discussion and comment purposes. They have not been peer-reviewed or been subject to the review by the NBER Board of Directors that accompanies official NBER publications.

(C) 2019 by Anya Samek, Arie Kapteyn, and Andre Gray. All rights reserved. Short sections of text, not to exceed two paragraphs, may be quoted without explicit permission provided that full credit, including $\odot$ notice, is given to the source. 
Using Vignettes to Improve Understanding of Social Security and Annuities

Anya Samek, Arie Kapteyn, and Andre Gray

NBER Working Paper No. 26176

August 2019

JEL No. H3,J26

\begin{abstract}
$\underline{\text { ABSTRACT }}$
Evidence shows that people have difficulty understanding complex aspects of retirement planning, which leads them to under-utilize annuities and claim Social Security benefits earlier than is optimal. To target this problem, we developed vignettes about the consequences of different annuitization and claiming decisions. We evaluated our vignettes using an experiment with a representative online panel of nearly 2,000 Americans. In our experiment, respondents were either assigned to a control group with no vignette, to a written vignette, or to a video vignette. They were then asked to give advice to hypothetical persons on annuitization or Social Security claiming, and were asked factual questions about these concepts. We found evidence that being exposed to vignettes led respondents to give better advice. For example, the gap between advised claim age for a relatively healthy person versus a relatively sick person was larger by nearly a year in the vignette treatments versus the control group. Further, the vignettes increased financial literacy related to these concepts by 10-15 percentage points. Interestingly, the mode of communication did not have a significant impact - the video and written vignettes were equally effective.
\end{abstract}

Anya Samek

Center for Economic and Social Research

and Department of Economics

University of Southern California

635 Downey Way

Los Angeles, CA 90089

anyasamek@gmail.com

Arie Kapteyn

Center for Economic and Social Research

and Department of Economics

University of Southern California

635 Downey Way

Suite 312

Los Angeles, CA 90089-3332

and NBER

kapteyn@usc.edu

\author{
Andre Gray \\ Center for Economic and Social Research \\ University of Southern California \\ 635 Downey Way \\ Los Angeles, CA 90089-3332 \\ andregra@usc.edu
}

Data were collected in the Understanding America Study (UAS141 and UAS 182) is available at https://uasdata.usc.edu/index.php 


\section{Introduction}

Individuals in the United States are increasingly responsible for their own financial security after retirement. Yet, evidence shows that they have difficulty understanding complex aspects of retirement planning and that financial literacy rates are low worldwide (Klapper et al., 2015). The result is that individuals may claim Social Security earlier, or utilize annuities less than is optimal, leading to poor financial security in later life (Benartzi et al., 2011; Poterba et al., 2011; Lusardi and Mitchell, 2007; 2011).

One solution is to provide financial education or more information about retirement planning. In one study, individuals who felt they had enough information about Social Security claiming were also more satisfied in retirement (Rabinovich and Samek, 2018). In other studies, visual tools and narratives helped individuals improve their financial literacy in basic concepts related to financial planning (Heinberg et al., 2014; Lusardi et al., 2017). Heinberg et al. (2014) found evidence that video and written narratives were equally effective at improving financial literacy, but that videos were more effective at improving self-efficacy surrounding decisions about retirement. However, the most effective content and mode of communication are still open questions.

Our paper is most related to two recent studies that investigated understanding of annuities and Social Security by using experiments in an online panel representative of the U.S. population. Brown et al. (2017) asked respondents to provide a lump sum amount they would be willing to pay for a permanent increase in Social Security monthly benefits, or to provide a lump sum amount they would have to be paid to accept a permanent decrease in monthly payments. Respondents provided divergent and inconsistent valuations. The implication is that consumers do not understand annuities and are not able to value them. In a follow-up study, Brown et al. (2019) found that inducing respondents to think jointly about the annuitization decision as well as how quickly or slowly to spend down assets in retirement led to improved respondents' valuation of annuities. We build on Brown et al. (2017) and Brown et al. (2019) using an online experiment to investigate the impact of a similar consequence message on decision-making and financial literacy. Different from Brown et al. $(2017$; 2018), this paper also evaluates the effect of modes of communicating the consequence message, including using video or a written narrative.

We propose that consequence messaging is a promising educational tool that can improve decision-making under uncertainty. The premise of consequence messaging is that while expected 
utility theory assumes that people make decisions by evaluating all possible consequences and their probability of occurrence, in complex situations that involve uncertainty, decisions are actually made without fully processing this information. A benefit of consequence messaging is that it describes the outcomes of multiple decisions under different states of the world. Hence, if individuals are asked to consider the consequences of an action, this should improve their understanding. In this sense, this paper is also related to Samek and Sydnor (2019), who use consequence graphs to help people understand the outcomes associated with different health insurance plan choices.

In this study, our first contribution is to evaluate how consequence messaging affects decision-making in the context of annuities and Social Security claiming. We chose these two concepts because both annuities and Social Security protect against longevity uncertainty and therefore could be affected by consequence messaging. Our second contribution is to assess different modes of communicating consequences by comparing video and written vignettes. We chose to compare videos and written modes of communication because these were also used in Heinberg et al. (2014) and because these are common ways of communicating through the internet.

In our vignettes, a 62-year old man is talking to his financial advisor about his plans for budgeting for his retirement. The financial advisor encourages the man to consider the consequences of different decisions. The financial advisor explains that outcomes depend partly on his decisions - i.e., how much money to spend down, and partly on uncertainty - i.e., the uncertainty surrounding how long the man can expect to live. The vignettes do not constitute a pure consequence message since the financial advisor also describes the basic features of the decision, for example by explaining the link between claiming age and level of Social Security benefits in the Social Security vignette.

To evaluate our vignettes, we conducted an experiment in the Understanding America Study (UAS). The UAS is a nationally representative probability-based internet panel ( $\mathrm{N}=6,000$ at the time of the study) housed at the University of Southern California. We recruited nearly 2,000 participants ages 30-70 to participate in the study and randomized them between-subjects in a $2 \times 3$ experimental design to either the Social Security or annuities condition, and to either receive no vignette, a written vignette, or a video vignette. The written and video vignette contained the same content but were presented either through video or as text on a webpage. In the valuing annuities vignette, the man is making a decision about whether to purchase an annuity. In the Social Security 
claiming vignette, the man is making a decision about when to claim his Social Security benefits.

We evaluate the impact of our vignettes on decision-making and understanding by using two main outcome variables. The first outcome is advice that the respondent would give a hypothetical person who is facing the decision of whether to annuitize or when to claim Social Security. Within-subjects, we experimentally vary whether the hypothetical person is in relatively good health or relatively poor health and evaluate this "spread" in advice by treatment. We consider this variable as most representative of decision-making, since we could not actually observe respondents' own decisions in these contexts. Further, asking respondents to give advice to a hypothetical person limits concerns about respondents' own wealth and health and allows us to manipulate health. The second outcome is the performance of respondents in a short quiz measuring financial literacy related to annuities or Social Security.

We find that, relative to the control group, respondents randomized to the vignettes advise significantly larger spreads of annuitization amounts and Social Security claim ages between the hypothetical person in relatively poor health and the hypothetical person in relatively good health. We take this as evidence that the vignettes affect decision-making, and provide suggestive data to indicate that this change leads to improved decisions. We also find that the vignettes significantly improve accuracy of responses to the financial literacy quiz. We take this as evidence that consequence messages improve understanding of annuities and Social Security, at least in the short-term. We do not find any evidence that one mode of communication is better than another; however, most respondents indicate that they prefer to receive the information in written form.

In what follows, Section 2 describes our experimental design. Section 3 summarizes our results. Section 4 provides a discussion and concludes.

\section{Experimental Design}

\subsection{Vignette Development}

We created two vignettes about the same 62-year old man and his financial advisor. Each vignette (in video format) was about 3 minutes long. The first vignette focused on annuities, and the second vignette focused on Social Security claiming age decisions. The written scripts for the vignettes and links to the video version, as well as screenshots of the video, are provided in Appendix B. In both vignettes, the 62-year old man is meeting with his financial advisor to discuss his plans for budgeting his retirement. 
The goal of both vignettes was to provide information about the consequences of living longer or shorter, stress the uncertainty in one's lifespan, and explain how this impacts the money that one can spend during retirement. In the annuities vignette, the financial advisor explained that an annuity acts as insurance against uncertain life expectancy: “Annuities are like insurance against outliving your money. You pay a premium up front, but then you're guaranteed a monthly payment until you die." However, the financial advisor does not actually advise purchasing an annuity. In the Social Security vignette, the financial advisor explains how monthly Social Security benefits change as a function of claiming age and clarifies that one does not need to claim in the same year as one retires from work: "Your retirement benefits depend on the age when you begin claiming. It's a tradeoff -- you can decide to claim earlier. In that case, you would have lower monthly benefits, but you'd also get to enjoy these benefits for a longer period." However, as before, the financial advisor does not actually advise delaying claiming.

\subsection{Participant Recruitment}

We conducted our experiment on the Understanding America Study (UAS), an online panel that is representative of the U.S. population. ${ }^{1}$ An advantage of using this panel is that we are able to understand the impact of our vignettes on the population they are meant to affect: i.e., older adults who are facing or will face the decision to annuitize or claim Social Security. Another major advantage of using the panel is that the UAS contains rich data on socio-economic status (SES) and cognitive abilities of respondents, which can be linked to the data that we collect.

We recruited a random sample of 2,150 Americans ages 30-70 from the UAS pool to participate in the study, and 1,808 respondents ultimately completed the study ( $84 \%$ response rate). ${ }^{2}$ Table 1 provides summary statistics of the sample. The average age of our respondents was 52 (S.D.=10.32). About 43\% were male and 57\% were female. $87 \%$ were white, $10 \%$ were black and $7 \%$ were Hispanic. Respondents came from a range of backgrounds. About $24 \%$ of the sample had an income of less than $\$ 30,00$ per year, and $26 \%$ had an income greater than $\$ 100,000$. About $25 \%$ of the sample had a high school education or less, while $14 \%$ had an education higher than a

\footnotetext{
1 UAS respondents are recruited through Address Based Sampling. This creates an effective way to reach a representative sample; respondents without prior access to the Internet receive a tablet and broadband Internet. Details are at https://cesr.usc.edu/data_toolbox/understanding_america_study.

${ }^{2}$ An additional 43 respondents started but did not complete the survey. As discussed in a later footnote, this rate does not differ by treatment assignment.
} 
bachelor's degree. Our data on SES and demographics comes from prior UAS surveys. As such, we are missing data on race for 6 respondents, and missing age for 1 respondent. We include missing dummies in the regressions for these respondents.

\subsection{Experiment Procedures}

The study was conducted in two waves - a smaller group was recruited July-November 2018 and follow-up data collection occurred April-July 2019. Our experimental design is presented in Table 2. Our $2 \times 3$ experimental design includes experimental variation in 1) whether respondents were asked about annuities or Social Security claiming and 2) whether respondents received no vignette (control group), a written vignette or a video vignette. Randomization was done at the respondent level, with the aim of randomizing an equal number of respondents to each of the six treatment cells. This resulted in about 300 observations in each treatment cell.

In the vignette treatments, following the vignette we also asked respondents to indicate whether they were able to fully view the vignette. Approximately $95 \%$ of respondents in the video vignette treatments and $99 \%$ of respondents in the written vignette treatments indicated that they could view the vignette fully, suggesting that most people were exposed to the intervention as expected. Despite the fact that a small minority could not view the vignettes, we include everyone randomized to each treatment in our analysis (i.e., we perform an intent-to-treat analysis).

At the end of the survey, all respondents received a short questionnaire that assessed the impact of the vignettes on decision-making and financial literacy. The questions also asked respondents to rate their concerns and expectations about retirement planning and indicate their preferences for receiving information. The questions are available in Appendix C. First, to assess decision-making, respondents were given two scenarios about the man from the video (in random order) and asked to give advice to the man about how much annuity to purchase or when to claim Social Security. ${ }^{3}$ The "long-life" scenario described the man as being in relatively good health and expecting to live a longer life: "based on his family history and his relative good health, Bill expects to live at least until he is 85 ". The "short-life" scenario described the man as being in relatively poor health and expecting to live a shorter life: "based on his family history and his

\footnotetext{
${ }^{3}$ We additionally randomized the name of the man in the scenario - which was either John or Bill. Further, a sub-set of respondents were exposed to an unrelated preference elicitation task before participating in our study. We add a control to our regressions to indicate this.
} 
relatively poor health, Bill expects to live until he is around 70". Relative to respondents in the control treatment, we expected respondents in the vignette treatments to give advice that was more responsive to the differences in the man's circumstances -- i.e., to have a larger "spread" between the advice in the "short-life" and "long-life" scenarios.

Second, to assess financial literacy related to annuities and Social Security claiming, we asked True/False questions about each concept. Respondents assigned to the annuity condition received four questions about annuities and respondents assigned to the Social Security condition received four questions about Social Security (in random order). ${ }^{4}$ The True/False statements dealt with basic features of annuities or Social Security benefits, such as, "An annuity is a financial product that pays a lump sum when you die" and, "You have to start claiming Social Security as soon as you stop working completely". We expected that if the consequence message were effective at improving understanding, then respondents randomized to the vignettes would get more of these questions correct than respondents randomized to the control group.

Third, we asked respondents how much importance they place on several concerns that people may have about retirement (in random order). The concerns were related to annuities or Social Security, depending on treatment to which the respondents were assigned. We developed these concerns with the aim of including some concerns that were related to considering consequences and some concerns that were not. Respondents were asked to value each concern on a five-point scale from "Not at all important" to "Very Important". For annuities, the consequencerelated concerns included (1) "The risk of not getting to spend most of your money in your lifetime", (2) "The risk of running out of money in your lifetime", and (3) "Uncertainty about how long you will live". For social security the items were (1) "The risk of claiming Social Security too late and not getting to enjoy the full benefits in your lifetime", (2) "The risk of claiming Social Security too early and getting a lower monthly payment during your lifetime" and (3) "Uncertainty about how long you will live". For both annuities and social security, the non-consequence-related concerns were (1) "Whether you have enough money saved up for retirement"; (2) "Leaving money for your children or other dependents" (see Appendix C for a full script).

Our hypothesis was that if the consequence message helps people consider the consequences of different outcomes, then respondents randomized to the consequence treatments would place a higher importance on the consequence-related concerns versus respondents

\footnotetext{
${ }^{4}$ Some of these questions were modeled after existing questions in the UAS.
} 
randomized to the control group. The remaining questions asked about preferences for mode of receiving communication about annuities or Social Security, and expectations about one's own claim or annuitization decisions.

Respondents received $\$ 5$ just for completing the survey and earned additional money by providing correct answers to the quiz..$^{5}$ In line with what is typically done in the UAS, respondents' earnings were deposited on their re-usable credit cards the first week of the following month.

\section{Results}

Our analysis includes all 1,808 respondents who completed the survey. Table 3 shows that we are balanced on all observable characteristics by treatment, suggesting that our randomization worked as intended. ${ }^{6}$ Because respondents randomized to a video vignette were more likely to have trouble viewing their treatment as compared to respondents randomized to a written vignette, we are unbalanced on ability to view the treatment. This biases downward our chance of observing an effect of the video vignette, as those unable to see the video effectively did not receive their treatment. Given this imbalance, we include regressions in Appendix Table A.1 that exclude respondents who were unable to view the vignettes. The results are qualitatively unchanged.

\subsection{Impact on Decision-Making}

To determine whether consequence messaging might affect decision-making, we investigated the advice respondents gave in the long and short-life scenarios. To evaluate decisionmaking on the extensive margin, we create a variable that takes the value of 1 if the advised amount to annuitize or the advised Social Security claim age is higher in the long-life scenario, and 0 otherwise. To evaluate decision-making on the intensive margin, we create a spread variable, which takes the difference between advice given in the long and short-life scenarios. We expect the spread to be positive, meaning that respondents should recommend annuitizing more money and claiming Social Security later in the long-life scenario relative to the short-life scenario. We further expect the spread to be larger in the vignette treatments, suggesting that the vignettes

\footnotetext{
${ }^{5}$ As noted earlier, a sub-set of respondents also completed unrelated tasks during the survey. These respondents took 15 minutes on average to complete the survey, and they earned an $\$ 8$ survey completion payment.

${ }^{6}$ An additional 43 (2.3\%) respondents started but did not complete the survey. This includes 5 in Annuities Control (1.7\%), 4 in Annuities Written (1.3\%), 6 in Annuities Video (2.0\%), 11 in Social Security Control (3.3\%), 7 in Social Security Written (2.2\%), and 6 in Social Security Video (3.2\%). There are no statistically significant completion rate differences between treatments (F-test $p$-value $=0.46)$.
} 
increase the responsiveness of respondents to information that changes longevity beliefs. This would amount to a change in the elasticity of a respondent's advised annuity purchase amount or claim age with respect to life expectancy.

In the annuities condition, 622 of $882(71 \%)$ respondents gave a directionally correct response, and in the Social Security condition 778 of 926 (84\%) of respondents gave a directionally correct response. Figure 1, Panel A summarizes the proportion of directionally correct responses by treatment. Although the number of directionally correct responses is larger for the treatment groups, the differences are not statistically significant (p-values from chi-squared tests comparing vignettes to control are between 0.06 and 0.19 ).

Given the high percentage of directionally correct recommendations that already exist in the control treatments, we suspect that we may face a ceiling in terms of finding treatment effects on this variable. Hence, Figure 1, Panel B summarizes the spread variable. In the annuities condition, the spread is measured as a percent of the total possible allotment of $\$ 250,000$. The average spread in the annuities condition is 15 percentage points $(\mathrm{SD}=23.9)$ and the average spread in the Social Security condition is 45 months $(\mathrm{SD}=35.2)$. We observe statistically significant differences in the spread by treatment for most comparisons. In the annuities condition, the spread is 7 percentage points larger in the written vignette treatment relative to the control group $(\mathrm{p}=0.002$ from a two-sided t-test) and 2 percentage points larger in the video vignette treatment relative to the control group, but this latter result is not statistically significant $(\mathrm{p}=0.233)$. The difference in spread when comparing the written and video vignettes is statistically significant $(p=0.04$ in a postestimation Wald test). In the Social Security condition, the spread is 11 months larger in the written vignette treatment relative to the control group $(\mathrm{p}<0.001)$, and 12 months larger in the video vignette $(\mathrm{p}<0.001)$. There is no statistically significant difference in the spread when comparing the written and video vignette $(p=0.715)$.

Figure 2 presents kernel density plots of the distribution of the spread variable. We find that the distributions of spread are also statistically significantly different in most comparisons. In the annuities condition, a Kolmogorov-Smirnov test comparing the distributions is statistically significant at the $1 \%$ level when comparing the written vignette to control $(\mathrm{p}=0.003)$, but not when comparing the video vignette to control $(p=0.065)$. In the Social Security condition, a Kolmogorov-Smirnov test comparing treatments to control is statistically significant in both the written vignette and the video vignette $(\mathrm{p}=0.003$ and $\mathrm{p}<0.001$ respectively). There are no 
statistically significant differences in the distribution of the spread when comparing the written and video vignette in either the annuity $(p=0.302)$ or Social Security $(p=0.785)$ treatments.

Table 4 provides regressions that confirm the results of our t-tests and show that our results are robust to the demographic, SES, numeracy and scenario order controls that we include. Column 1 uses the binary 1/0 variable of directionally correct recommendations as an outcome variable, while columns 2 and 3 use the spread as the outcome variable. In column 3, we additionally control for the advice given in the short-life scenario in order to compare scenario differences with similar baseline advised annuitization amounts or claim ages. The treatment effects when comparing each vignette treatment to the control group remain large and statistically significant in all specifications. Post-estimation tests comparing the written and video vignettes do not yield statistically significant results (p-values between 0.06 and 0.94). In Appendix Table A.1, we run the same analysis but excluding who said they had problems viewing the vignette. Appendix tables A.2 and A.3 display coefficients for the full list of demographic and SES controls found in Table 4.

The advised spread treatment effects that we observe in column 2 are economically relevant. For example, for a 62 year-old man, delaying Social Security claiming by 11 months results in $6.1 \%$ higher benefits each month. ${ }^{7}$ Similarly, an investment of $5.5 \%$ of $\$ 250,000$ in an annuity amounts to $\$ 13,750$, which at a payout rate of $6 \%$ per year (an average market rate for a 62 -year old male) ${ }^{8}$ amounts to an additional $\$ 70$ per month.

\subsection{Impact on Financial Literacy Surrounding Retirement Planning}

We next investigate the impact of our vignettes on understanding of annuities and Social Security. The average percentage of correct True/False responses in the annuities condition was $87.4 \%$ (S.D. $=19.5$ ) and the average percentage of correct True/False responses in the Social Security scenario was 89.8\% (S.D.=19.5). Figure 3 shows the percent correct by treatment. Relative to the control group, the vignettes showed a higher percent correct by about 10 percentage points for the annuities condition and 14 percentage points for the Social Security condition. We find that in the annuities condition, both written and video vignettes showed statistically

\footnotetext{
${ }^{7}$ Estimates based on Social Security benefit tables found at https://www.ssa.gov/planners/retire/1943.html

${ }^{8}$ This rate is taken from the following Forbes article: Carey, Matt. The Best Fixed Annuities Available in 2018, 1 Aug 2018, https://www.forbes.com/sites/mattcarey/2018/08/01/the-best-fixed-annuities-available-in2018/\#eccab054df1f
} 
significantly higher percentages of correct answers versus control $(\mathrm{p}<0.001$ for either vignette in t-tests comparisons with control). In the Social Security condition, the written and video vignettes also showed statistically significantly higher percentages of correct answers versus control ( $<<0.001$ for both vignettes). The vignettes were not statistically different from each other in either condition. Table 4 presents these results as a regression in specification 4, controlling for demographics, SES, scenario order and numeracy.

\subsection{Impact on Concerns and Expectations}

We next evaluate whether the vignette treatments increased the importance that respondents placed on consequence-related concerns about retirement and on the respondents' reported own plans about annuitization and claiming. While these are the variables we might ultimately wish to affect, we should note that it is generally difficult to move these variables. For example, Perez-Arce et al. (2019) found that an intervention with information about spousal benefits associated with Social Security claiming age affected the advice that respondents gave in hypothetical situations but did not affect respondents' own expected claiming ages. In addition, with regards to the Social Security claiming age, we did not have an a priori expectation of which direction it should move by treatment, since this would depend on self-assessed longevity. Finally, with respect to annuitization, an individuals' expected wealth at retirement and access to private pensions are unobserved variables that affect the reports.

We did not find an impact on either consequence-related concerns or on expected annuitization or Social Security claim age. The average importance placed on the 3 consequencerelated concerns was 3.51 (S.D. $=0.90$ ) on a 5-point Likert scale, while the average importance placed on the 2 concerns unrelated to consequences was 3.75 (S.D. $=0.94$ ) on the same scale. The difference is small and does not seem to differ by treatment. Figure 4 displays the difference in importance placed on consequence-related concerns over non-consequence-related concerns, by treatment. When looking at annuities and Social Security separately, we find positive but not statistically significant treatment effects on consequence-related concerns over non-consequencerelated concerns in the video vignette ( $t$-test comparisons to control yield $\mathrm{p}=0.07, \mathrm{p}=0.14$ respectively). Column 5 in Table 4 confirms the result that there are no statistically significant differences by treatment on this measure. 
The treatments generally did not have an impact on the respondents' claiming age or level of annuitization. Restricting our analysis to respondents who are not yet old enough to claim Social Security (age less than 62), on average respondents in the annuities condition reported a likelihood of annuitizing in the future of 2.8 (S.D. $=0.95$ ) out of 5 . While the video vignette increased the likelihood over control by 0.22 (t-test comparison to control yields $\mathrm{p}=0.02$ ), the written vignette had no statistically significant effect $(\mathrm{p}=0.08)$. In the Social Security condition, respondents on average answered that they would begin collecting Social Security benefits at age 65.6 (S.D.=2.75). Neither the written nor the video vignette had an effect on expected claiming age $(p=0.42$ and $p=0.56$ respectively).

\subsection{Further Analysis}

\subsubsection{Welfare}

While we observed large impacts on the spread in advice by treatment, we next attempt to evaluate whether this effect reflects a welfare improvement, given the limited information we provided to the respondents about the annuity instrument and Social Security claim benefit. This analysis is exploratory, since we did not identify this as an issue a priori and since respondents were given limited information, making complex calculations challenging. Hence, we may think of this exercise as merely suggestive.

To study welfare effects, we transform respondents' advice in both scenarios into the present value of a stream of monthly payments. We take advantage of the fact that the only difference between the two scenarios is life expectancy, which increases by 15 years in the longlife scenario relative to the short-life scenario. For simplicity, we ignore the fact that there is some uncertainty in longevity in each scenario. In the annuities condition, we calculate a monthly payout assuming a fixed rate annuity with an annual payout rate of $6 \%$.

In the Social Security condition, we follow the claim age tables on the Social Security website to convert the respondents' recommended claim ages into a percentage of their full monthly retirement benefit, starting at $70 \%$ if they claim at age 62 , and increasing on average 0.4 percentage points each month delayed after that. ${ }^{9}$ We allow our percent of monthly benefit value

${ }^{9}$ Estimates based on Social Security benefit tables found at https://www.ssa.gov/planners/retire/1943.html 
to keep increasing at this increment until 70 , in order to match the possible responses in our simplified scenario. We assume the maximum 2019 full retirement benefit of $\$ 2,861$ to convert this percentage value into dollar terms.

Given a fixed life expectancy, the present value of a monthly payout in either condition is as follows, where $n$ represents the number of months of expected life left, and $r$ is the prevailing discount rate, which we assume to be $3 \%$ :

$$
\text { Monthly Payout }(\$) *\left\{\frac{1-\frac{1}{(1+r)^{n}}}{r}\right\}
$$

Table 5 shows vignette treatment effects on the present value of the respondent's long-life recommendation, controlling for the short-life recommendation as well as demographics and SES. The written vignette treatments increases present value by $\$ 2,244$ in the annuities condition $(p=0.003)$ and $\$ 2,071$ in the Social Security condition $(p=0.019)$. The video vignette treatments show positive but not statistically significant effects, although Wald post-estimation tests comparing written to video do not show significant differences ( $\mathrm{p}=0.093$ in the annuities condition and $\mathrm{p}=0.343$ in the Social Security condition). This preliminary analysis suggests that both treatments not only increased the spread of the recommended values, but also improved welfare for the hypothetical person.

\subsubsection{Interaction Effects}

Our final question is whether we observe heterogeneous treatment effects by age, race and cognitive ability. We consider age because we expect that vignettes may be more effective for people who are younger and have therefore had less exposure to or thought less about annuitizing and claiming decisions. We consider race because we are interested in exploring whether the video vignette, which featured white actors, was more salient for white respondents relative to other races or ethnicities. Finally, we consider cognitive ability because we are interested in understanding whether our treatments help narrow the gap in financial literacy between higher and lower cognition respondents. Tables 6 and 7 explore the possibility of heterogeneity in vignette treatment effects on both our binary directionally correct variable and our spread variable. Columns 1 and 2 in both tables display the interaction of the vignettes with respondent age. Older adults are more likely to have had exposure to retirement planning concepts (and some may have 
already made their own decisions about annuitization or claiming Social Security), and may therefore be expected to respond less to the treatment vignettes. We find that treatment effects do not vary significantly with respect to age.

Columns 3 and 4 use the interaction of treatments with black respondents. We might expect the video vignette to be less salient for black respondents, as the video featured a white financial advisor and advisee, and some evidence in the medical field suggests that advice is taken more seriously from professionals of the same race as the patient (Hill et al., 2018; Boulware et al., 2016). We do not find evidence of this. The coefficients on the video vignette and race interaction are similar to the coefficients on the written vignette and race interaction.

Columns 5 and 6 display the interaction of treatment with numeracy. In general, treatment effects appear not to vary significantly with respondent's numeric skills (while the coefficients appear statistically significant in the written vignette of the annuities condition, the effect size is small). Similar results are observed when we use a financial literacy score ${ }^{10}$ or educational attainment in Appendix Tables A.4 and A.5.

\section{Discussion and Conclusion}

Use of annuities and Social Security claim age decisions are important in the retirement planning process since they substantially affect wellbeing and economic security in retirement. Research finds that people tend to under-utilize annuities and claim Social Security earlier than is optimal. In this study, we conducted an experiment with a large representative sample of Americans to investigate the impact of short written and video educational tools on decisionmaking and financial literacy surrounding these complex concepts. Our survey included nearly 2,000 Americans ages 30-70 years old. We randomized respondents in a $2 \times 3$ design to either receive the annuity or Social Security scenario, and to either receive no vignette, a written vignette or a video vignette. The vignettes provided information about the consequences of making different decisions about annuitization and Social Security claim age, respectively.

We found that our vignettes affected decision-making and financial literacy. Our measure of decision-making was the advice that respondents gave to a hypothetical person about how much

\footnotetext{
${ }^{10}$ This is another measure available in the UAS that is highly correlated with numeracy. It is based on the National Financial Capability Study (NFCS), a project of the FINRA Investor Education Foundation:

https://www.usfinancialcapability.org/
} 
to annuitize and when to claim Social Security. We believe this measure is better than using own decisions, since we were able to experimentally manipulate the perceived health of the hypothetical person in each scenario, and since the responses could be de-coupled from other aspects of the respondents' own circumstances, such as amount of money available for annuitization. In the vignette treatments, respondents' advice was more responsive to the health circumstances of the hypothetical person than in the control group. Further, in the vignette treatments, respondents answered more True/False questions correctly about the concepts than in the control group.

We did not find any impact of our vignettes on self-reported concerns about retirement planning or on expected annuitization decisions and claim age. We might have expected this, since related work also found that own expected decisions are more difficult to influence through short experimental manipulations (Perez-Arce et al., 2019). Hence, we view it as a positive that our main measure included the advice to the hypothetical person, since absent this measure, we might have concluded that short messages do not have an impact on decision-making. In practice, short messages may be more impactful if they are delivered at the time of decision, such as together with the information that Social Security might send individuals about their eligibility to claim, or bundled with information about annuity products. We leave this idea for future research.

We also collected data on respondents' preferences for receiving communications about annuities and Social Security. Respondents were given a multiple choice question that included the following modes of communication: watch a video online, read an article online, or receive information in the mail. The most commonly selected preference for receiving communications was receiving information in the mail (34.13\% of respondents), followed by reading an article online ( $28.54 \%$ of respondents) and watching a video online ( $25.5 \%$ of respondents). We find that preferences varied somewhat by age, with participants over 50 being $33 \%$ more likely to prefer receiving information in the mail than younger respondents. Since both written and video modes of communication proved equally effective, the choice of which to use in practice may depend both on preferences and on cost. Disseminating videos online has a high fixed cost (i.e., to produce the video) but a low marginal cost (sending out the link). This low marginal cost means that disseminating videos online may be easy to quickly scale to a large number of viewers. On the other hand, providing information through the mail may have lower fixed cost (no need to produce a video) but has higher marginal cost (the cost of printing and stamps). 
Our study leaves several questions open for future work. From a theoretical perspective, research should try to better understand what it is about consequence messaging that makes it effective. This work should include considering why consequence messaging works for conveying factual information, but is not particularly effective at increasing concerns about consequences. It would be interesting to understand whether people place more weight on negative or positive consequences. Future work could also address other types of consequence messaging, for example, addressing risk perception in a broader range of settings. 


\section{References}

Benartzi, Shlomo, Alessandro Previtero, and Richard H. Thaler. "Annuitization puzzles." The Journal of Economic Perspectives 25, no. 4 (2011): 143-164.

Boulware, L. Ebony, Lisa A. Cooper, Lloyd E. Ratner, Thomas A. LaVeist, and Neil R. Powe. "Race and trust in the health care system." Public health reports (2016).

Brown, Jeffrey R., Arie Kapteyn, Erzo F.P. Luttmer, and Olivia S. Mitchell. "Cognitive Constraints on Valuing Annuities." Journal of the European Economic Association 15, no. 2 (2017): 429-462.

Brown, Jeffrey R., Arie Kapteyn, Erzo FP Luttmer, Olivia S. Mitchell, and Anya Samek. "Behavioral Impediments to Valuing Annuities: Complexity and Choice Bracketing." PRC WP2019-5 Pension Research Council Working Paper (2019).

Heinberg, Aileen, Angela A. Hung, Arie Kapteyn, Annamaria Lusardi, Anya Savikhin Samek, and Joanne Yoong. Five steps to planning success. Experimental evidence from US households. No. w20203. National Bureau of Economic Research, 2014.

Hill, Andrew, Daniel Jones, and Lindsey Woodworth. "A Doctor Like Me: Physician-Patient Race-Match and Patient Outcomes." (2018).

Klapper, Leora, Annamaria Lusardi, and Peter Van Oudheusden. "Financial literacy around the world." World Bank. Washington DC: World Bank (2015).

Lusardi, Annamaria, and Olivia S. Mitchell. "Baby boomer retirement security: The roles of planning, financial literacy, and housing wealth." Journal of Monetary Economics 54, no. 1 (2007): 205-224.

Lusardi, Annamaria, and Olivia S. Mitchell. Financial literacy and planning: Implications for retirement wellbeing. No. w17078. National Bureau of Economic Research, 2011.

Lusardi, Annamaria, Anya Samek, Arie Kapteyn, Lewis Glinert, Angela Hung, and Aileen Heinberg. "Visual tools and narratives: New ways to improve financial literacy." Journal of Pension Economics \& Finance 16, no. 3 (2017): 297-323.

Perez-Arce, Francisco, Joanne Yoong, Lilia Rabinovich. "The Effect of Informational Prompts about Spousal Benefits on Social Security Claim Intentions." Working Paper, 2019.

Poterba, James M., Steven F. Venti, and David A. Wise. "Were They Prepared for Retirement? Financial Status at Advanced Ages in the HRS and AHEAD Cohorts." In Investigations in the Economics of Aging, pp. 21-69. University of Chicago Press, 2011.

Rabinovich, Lila, and Anya Samek. "' No Regrets": Qualitative Evidence on Early Claiming of Social Security Retirement." Journal of Aging Studies 46 (2018): 17-23. 
Samek, Anya, and J. Sydnor. Simplifying Health Insurance Choice with Consequence Graphs. Technical report, University of Wisconsin-Madison, 2017.

Weller, J. A., Dieckmann, N. F., Tusler, M., Mertz, C. K., Burns, W. J., and Peters, E. (2013). Development and testing of an abbreviated numeracy scale: a Rasch analysis approach. J. Behav. Decis. Mak. 26, 198-212. doi: 10.1002/bdm.1751 


\section{Main Tables \& Figures}

Table 1: Summary Statistics

\begin{tabular}{lcc}
\hline \hline & Mean & SD \\
\hline Age & 51.87 & 10.32 \\
Gender - Male & 0.43 & 0.50 \\
White & 0.87 & 0.34 \\
Black & 0.10 & 0.30 \\
Span./Hisp/Latino & 0.07 & 0.25 \\
Other Race & 0.09 & 0.29 \\
$\$<30,000$ & 0.24 & 0.43 \\
$\$ 30,000-59,000$ & 0.27 & 0.45 \\
$\$ 60,000-99,999$ & 0.23 & 0.42 \\
$\$ 100,000+$ & 0.26 & 0.44 \\
High School or Less & 0.25 & 0.43 \\
Some College & 0.21 & 0.41 \\
Assc. College Degree & 0.17 & 0.38 \\
Bachelor & 0.22 & 0.42 \\
Master/Prof/Dr & 0.14 & 0.35 \\
Scenario Order & 0.50 & 0.50 \\
Numeracy Score & 50.96 & 8.82 \\
Missing Demographics & 0.00 & 0.00 \\
Could not View & 0.02 & 0.14 \\
\hline \hline
\end{tabular}

Notes: This table shows summary statistics of demographics (age, gender and race), socioeconomic status (household income and highest level of education attained), order in which the scenarios were presented, numeracy and missing data. The numeracy score is taken from an 8-item numeracy scale designed by Weller et al. (2013), and then compiled into a single measure using an Item Response Theory (IRT) model.

Table 2: Experiment Design

\begin{tabular}{lcccc}
\hline & Control & Written Vignette & Video Vignette & Total \\
\hline Annuities & 286 & 302 & 294 & 882 \\
Social Security & 314 & 307 & 305 & 926 \\
\hline
\end{tabular}

Notes: This table shows the number of respondents in the analysis sample randomized to each treatment. 


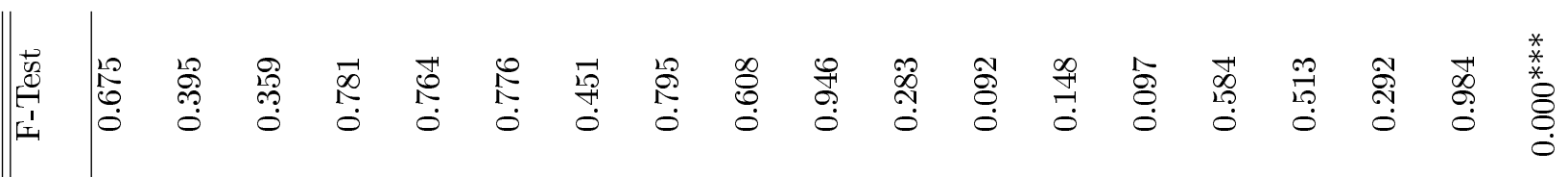

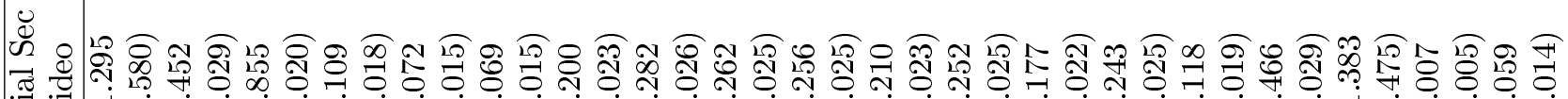

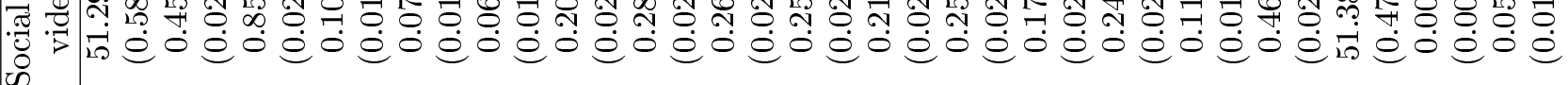

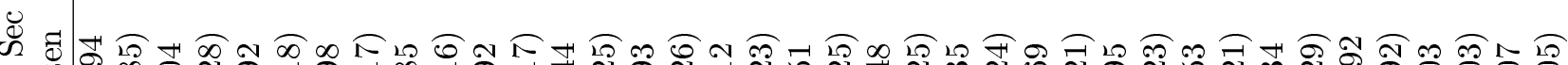

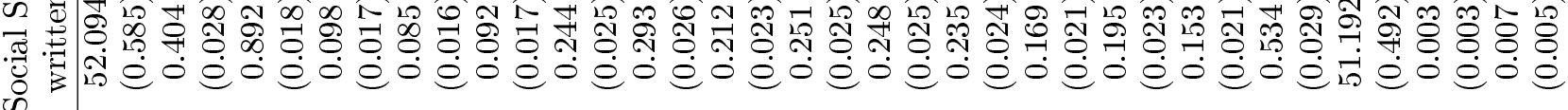

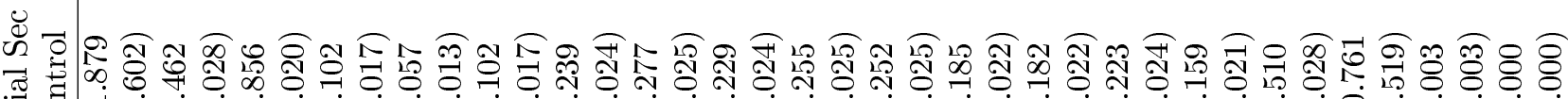

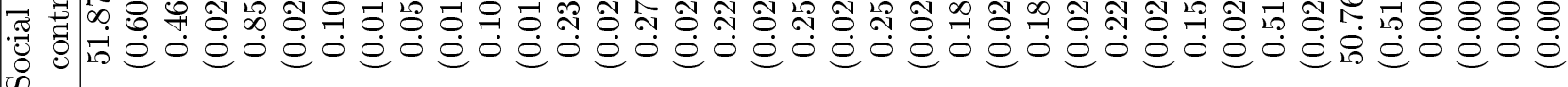

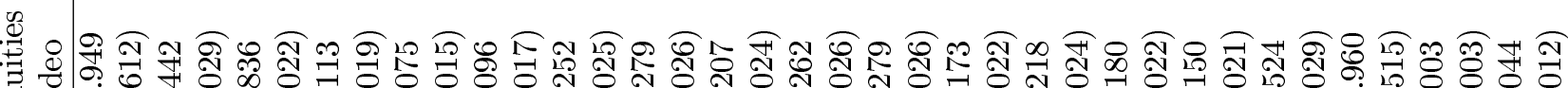

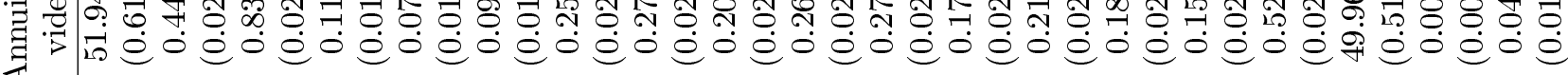

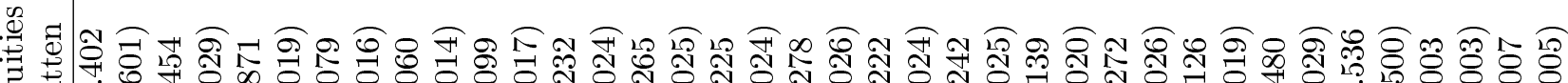

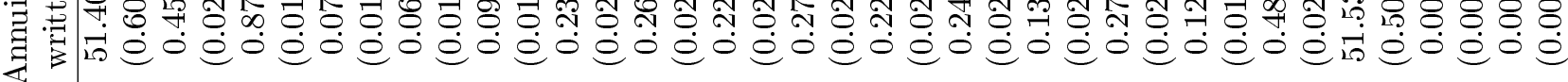

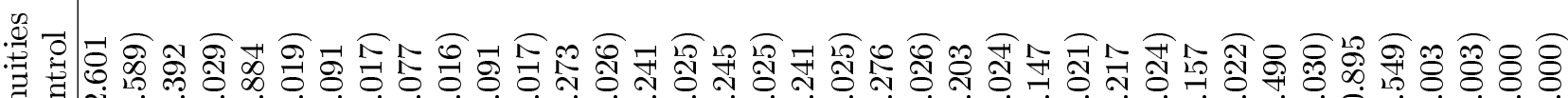

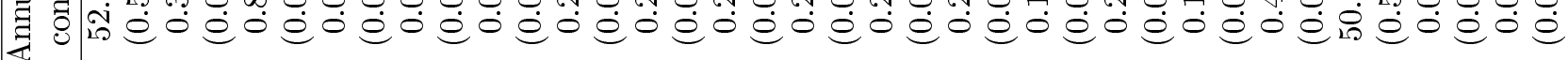

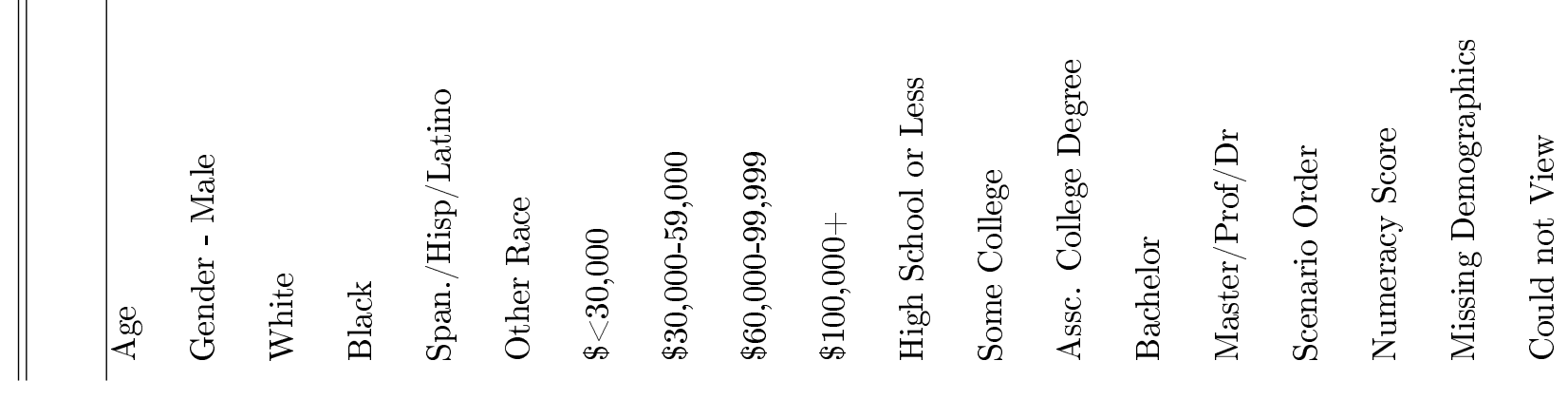

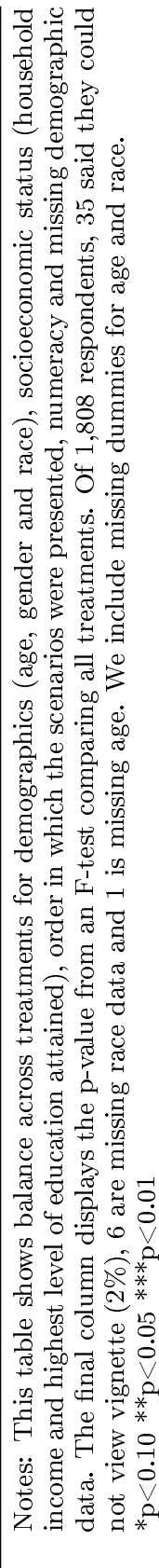


Figure 1: Long and Short Life Scenarios by Treatment

Panel A: Directional Accuracy
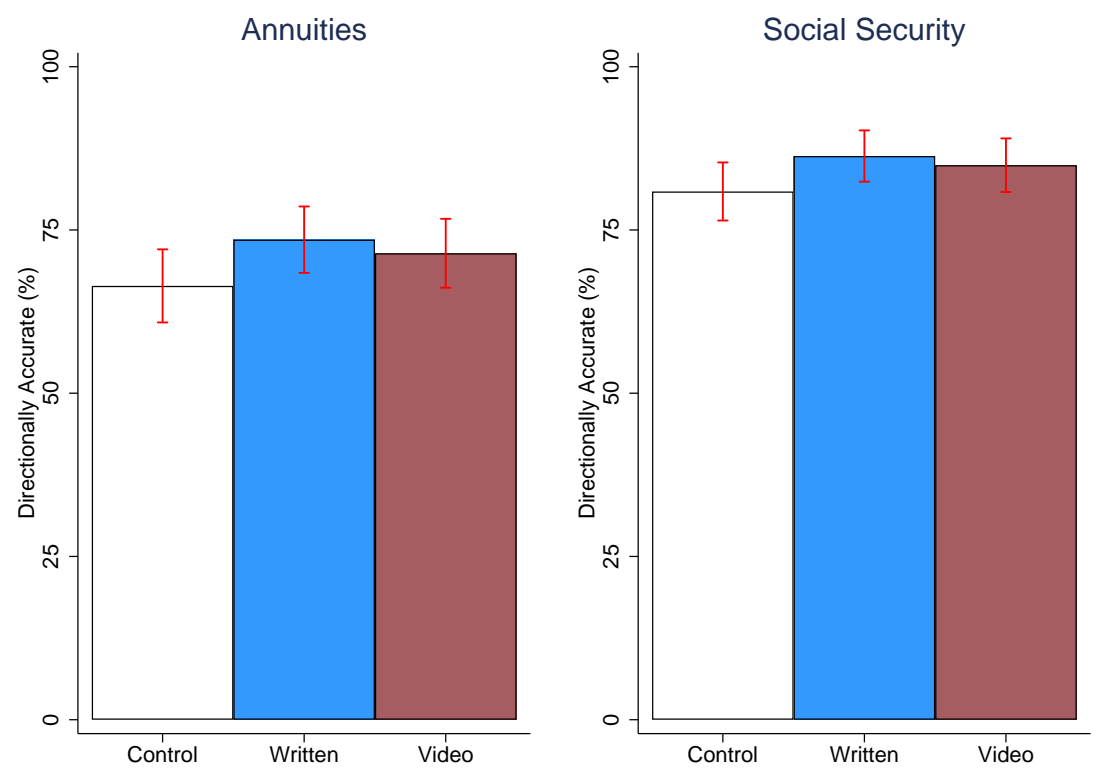

Panel B: Difference between Scenarios
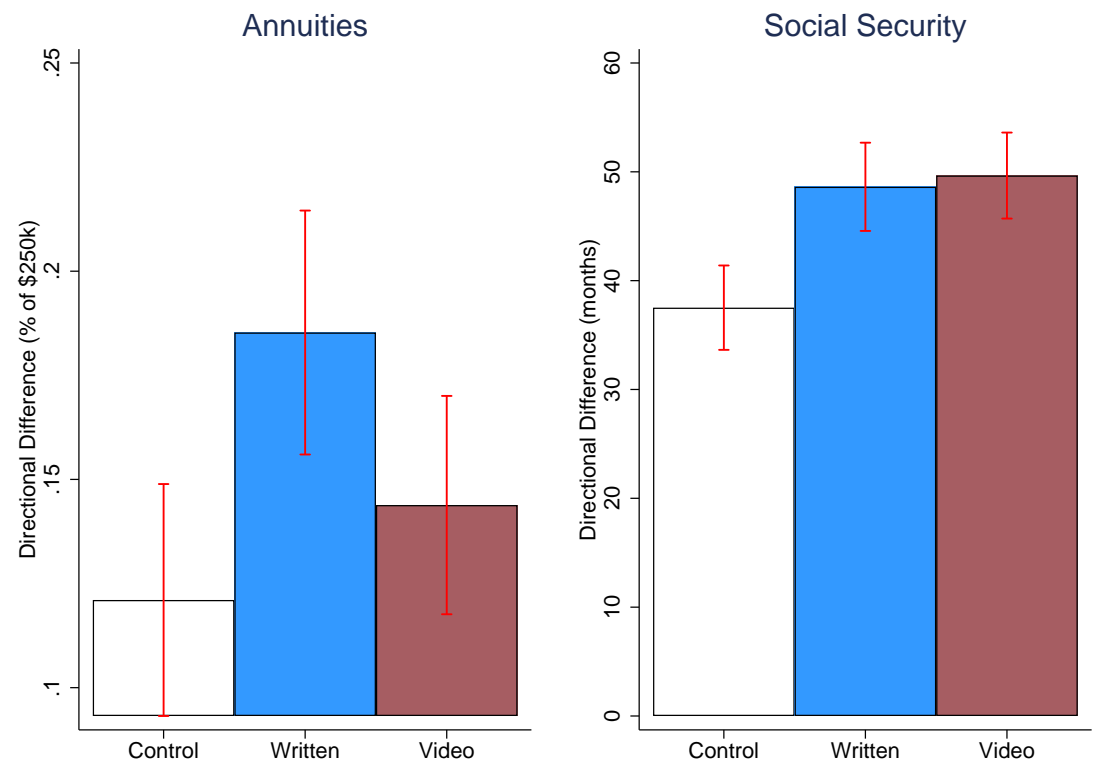

Notes: This figure shows mean and standard error bars for the proportion of directionally accurate respondents (Panel A) and the raw difference in scenario recommendations (Panel B) by treatment and condition (either annuity or Social Security). 
Figure 2: Distribution of Difference in Long and Short Life Scenarios
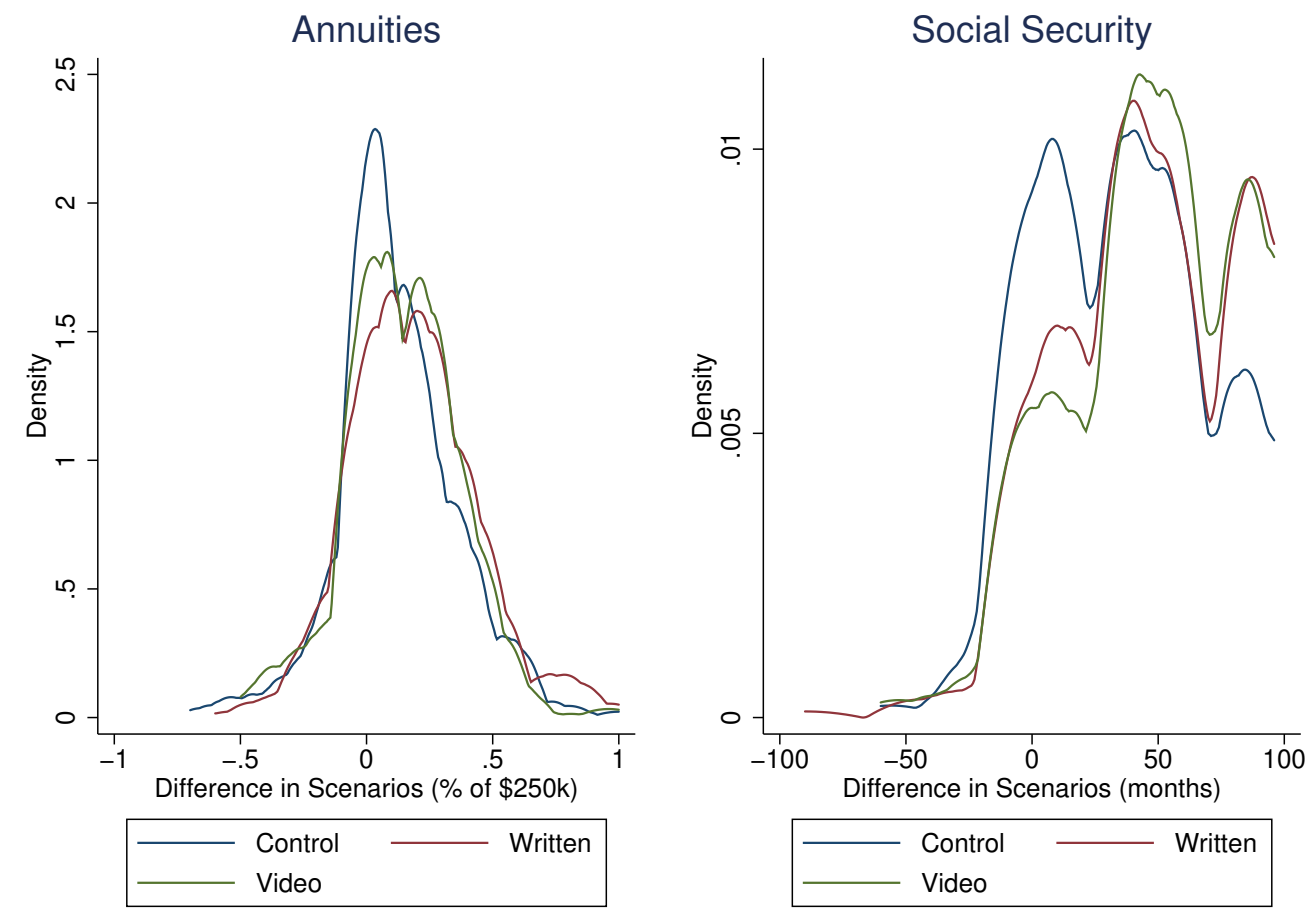

Notes: This figure shows a kdensity plot of the raw difference between the short life and long life scenarios for Annuities and Social Security, by treatment. 


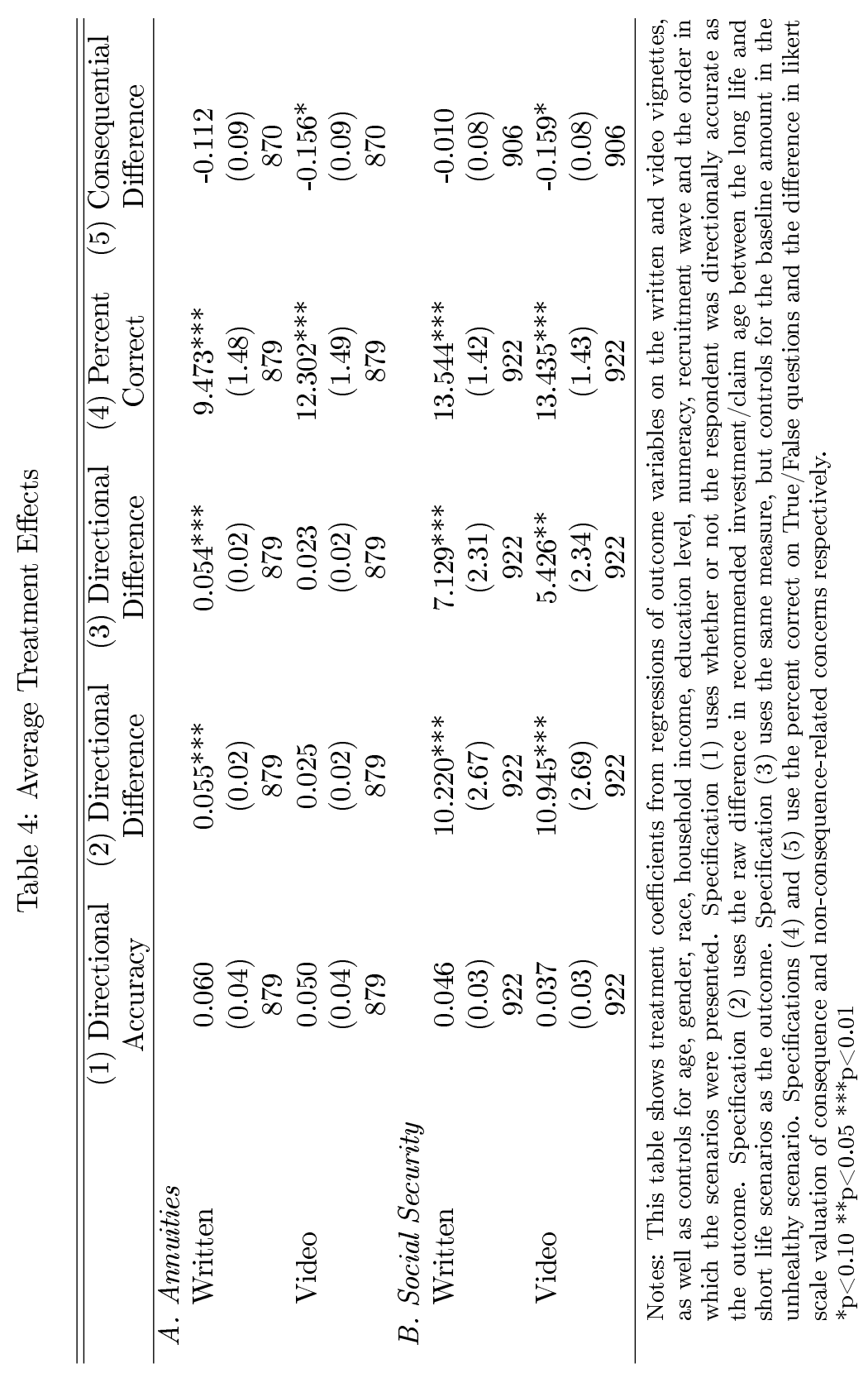


Figure 3: Percentage Correct True/False Questions by Treatment
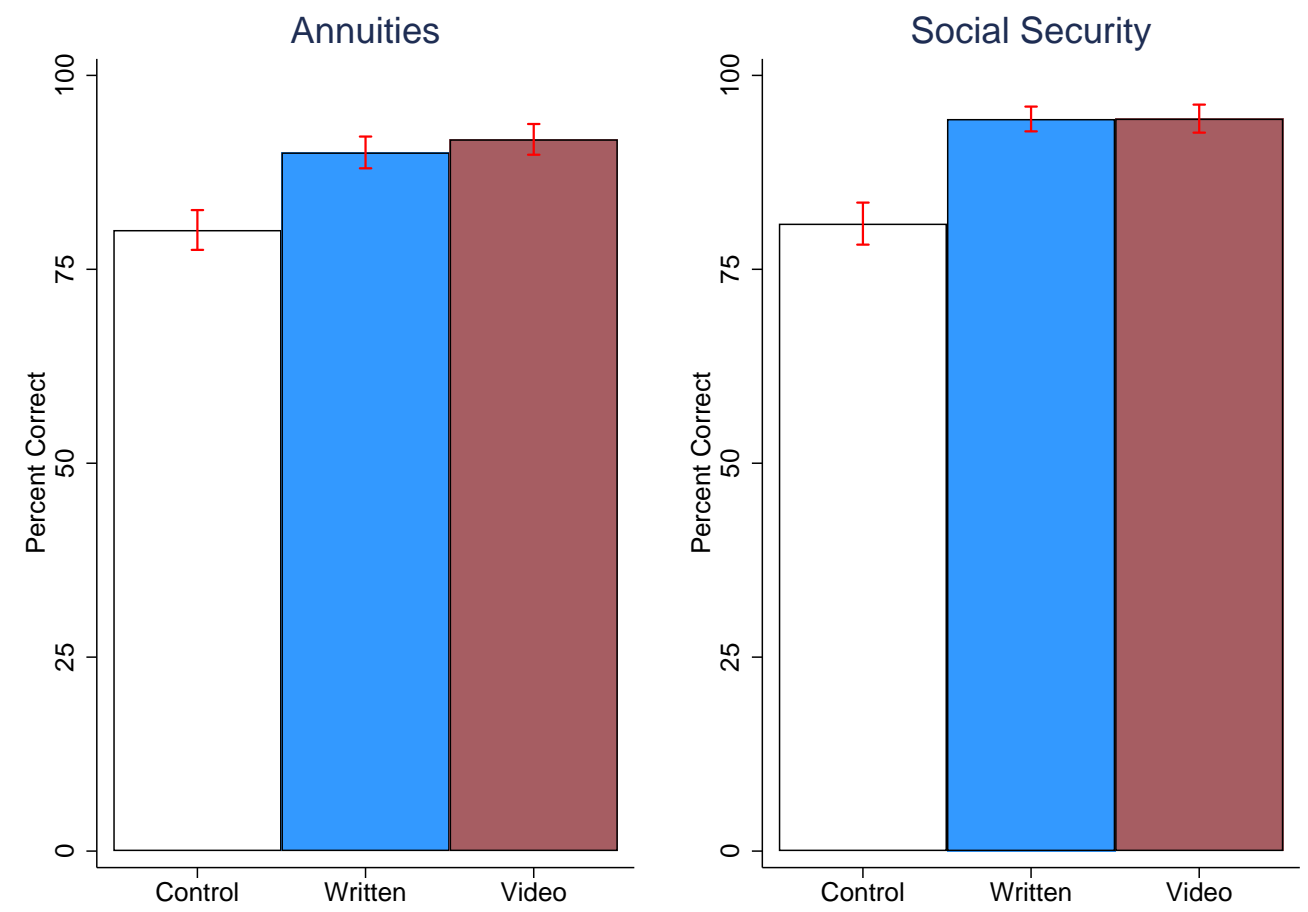

Notes: This figure shows mean and standard error bars for the percent correct on 4 True/False questions by treatment and condition (either annuity or Social Security). 
Figure 4: Consequence Related Difference
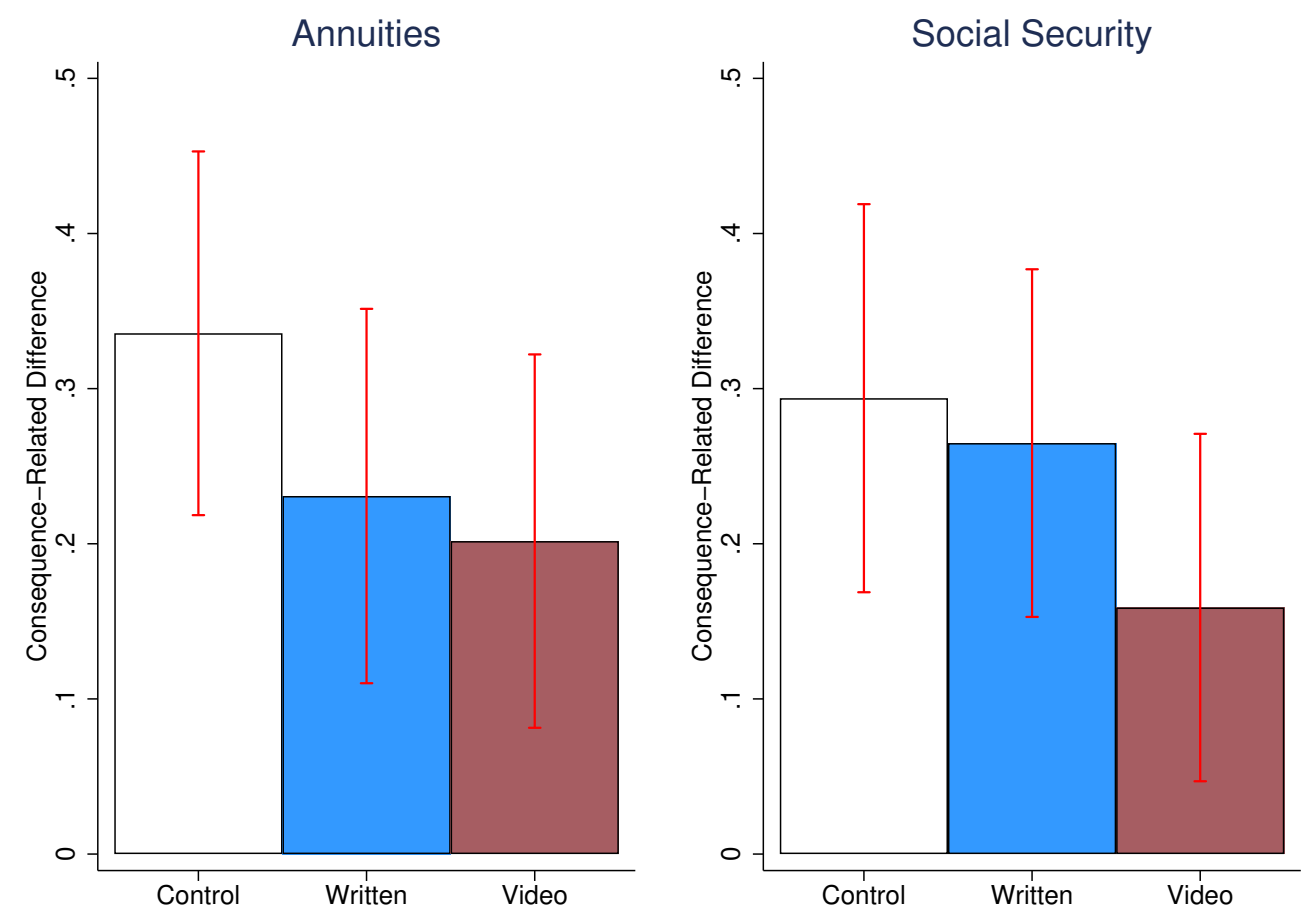

Notes: This figure shows mean and standard error bars for the difference in the likert scale valuation of non-consequence related concerns (the mean of two concerns) and consequence-related concerns (the mean of three concerns), by treatment and condition (either annuity or Social Security). 


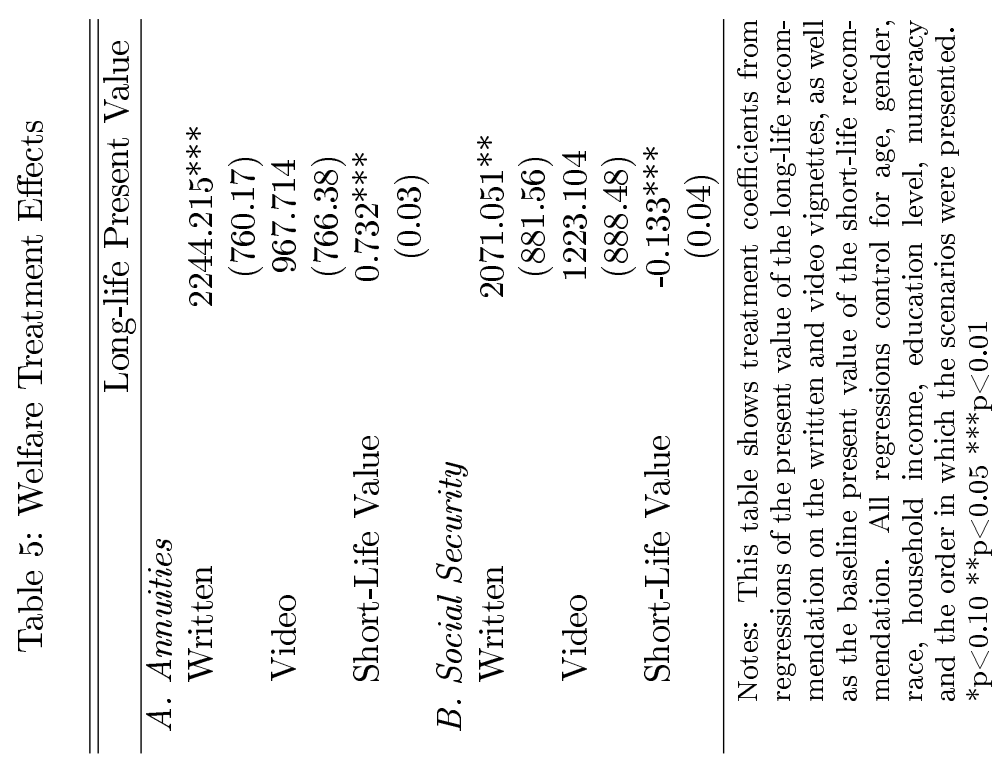




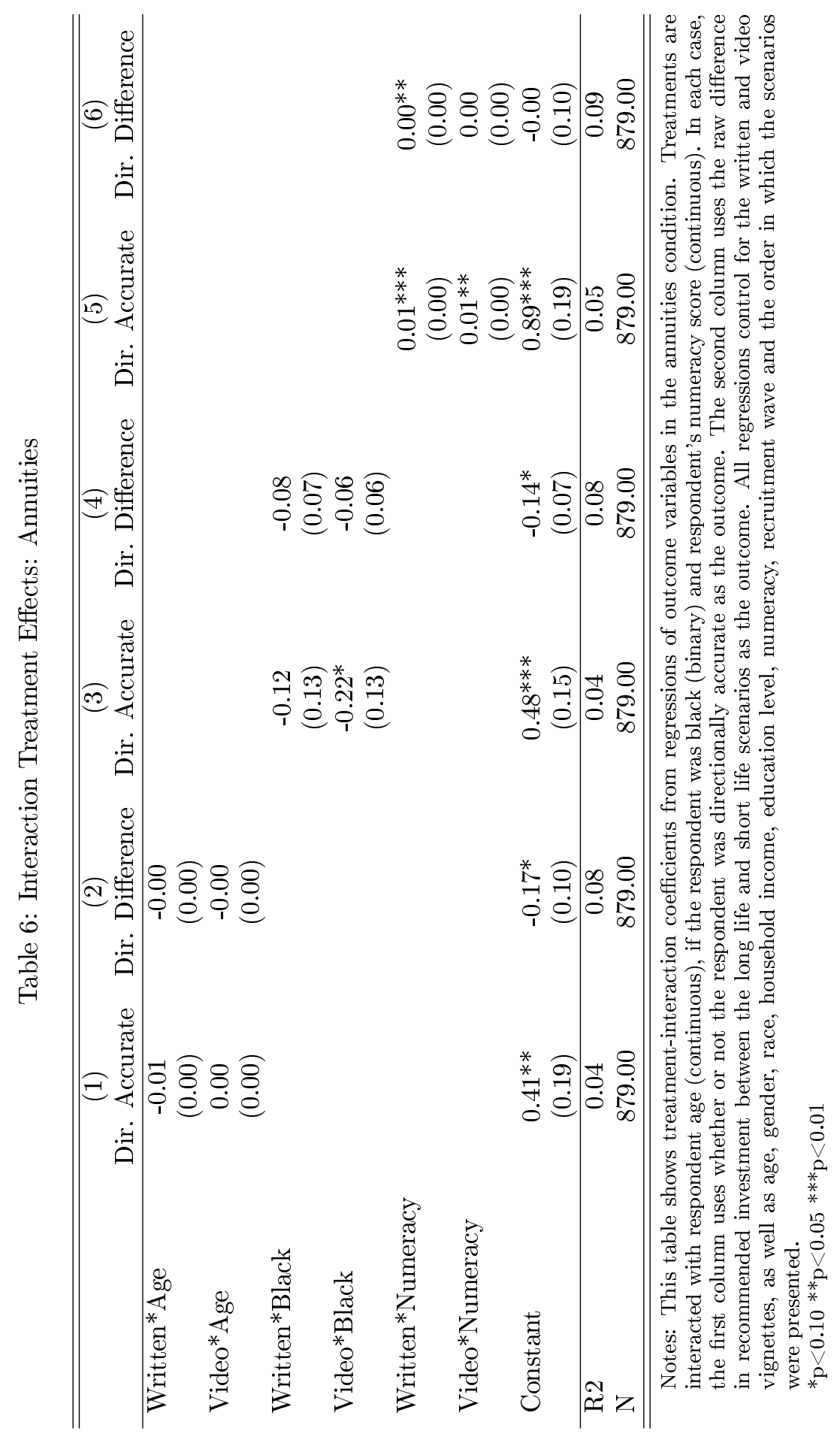




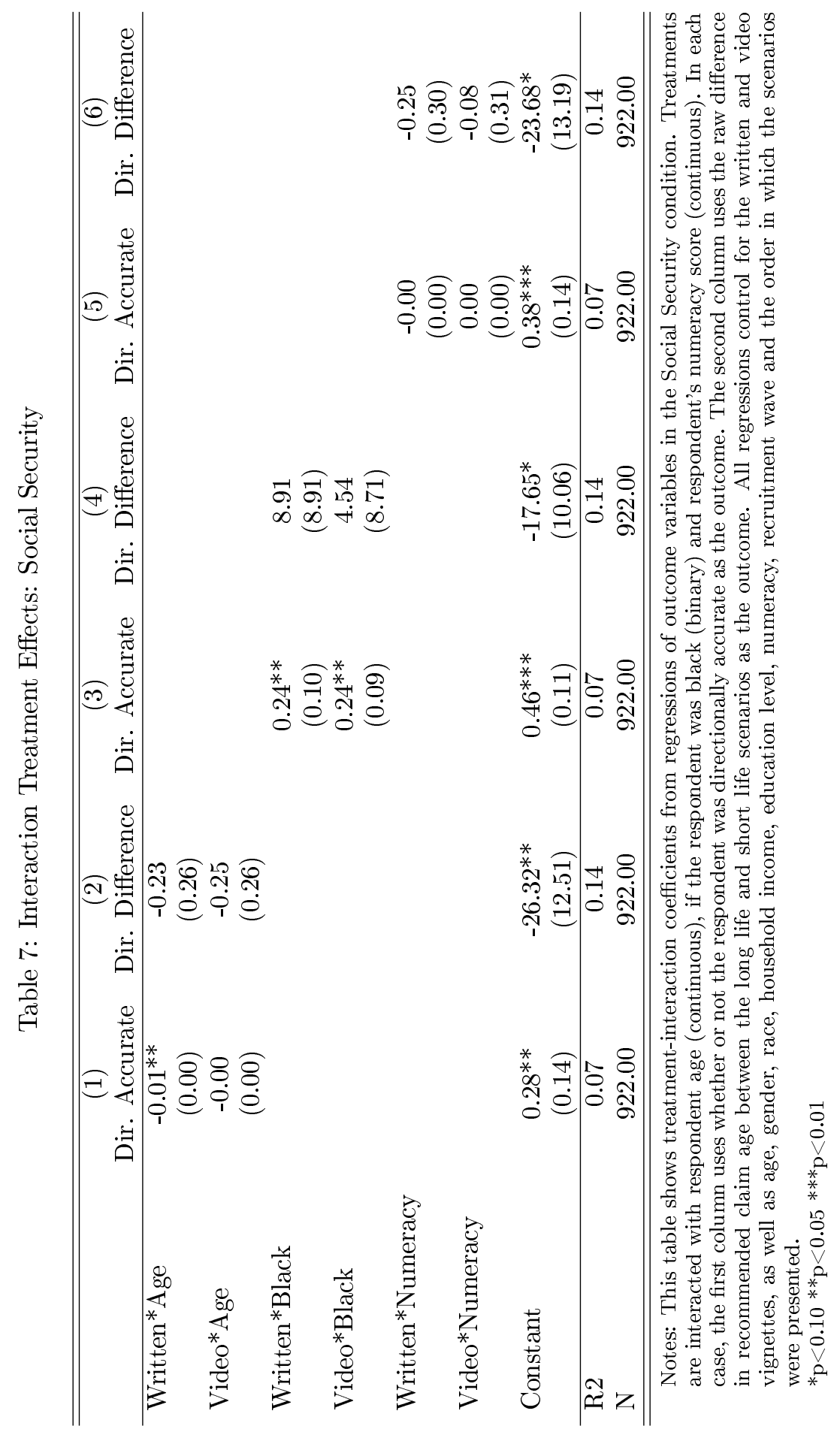




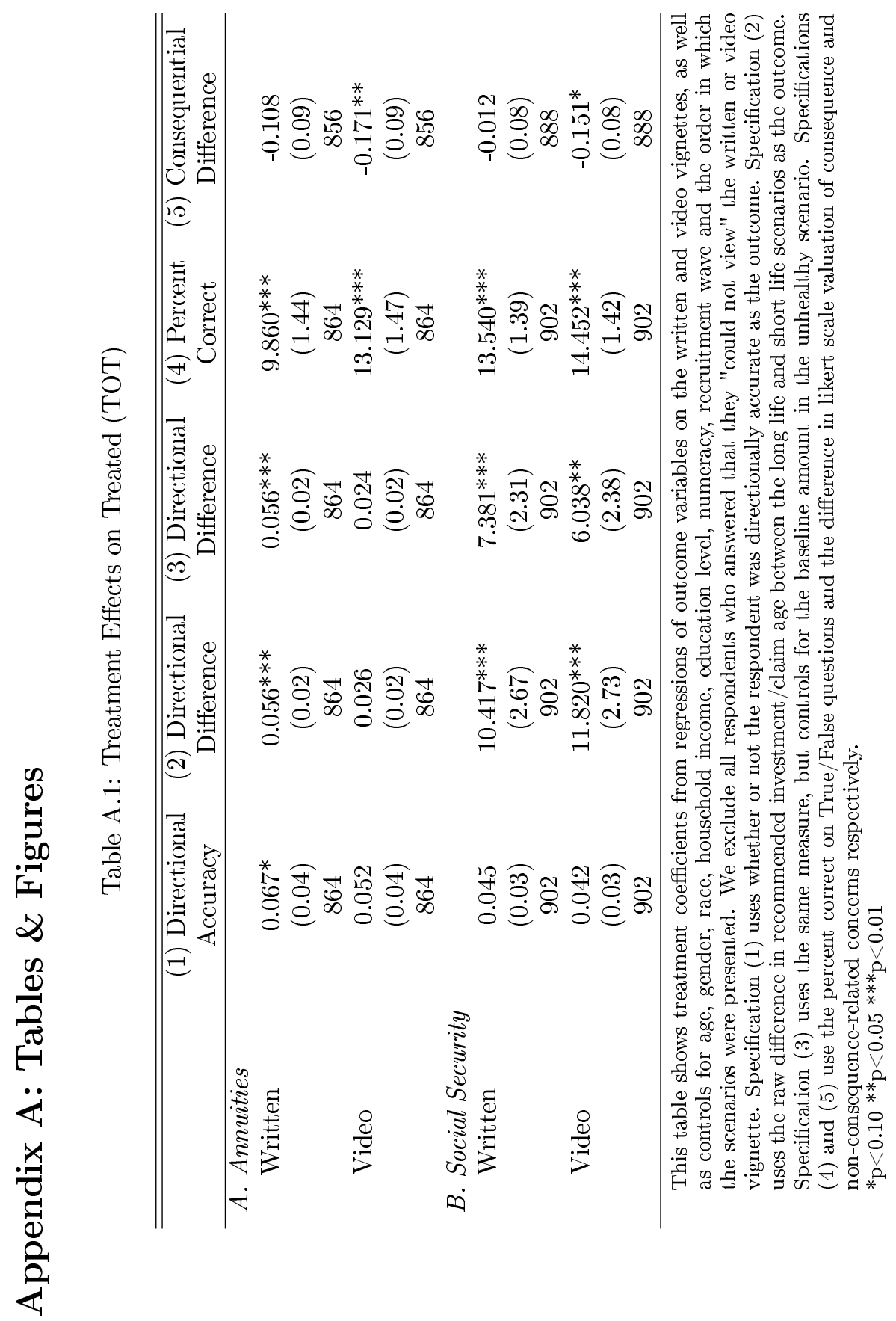




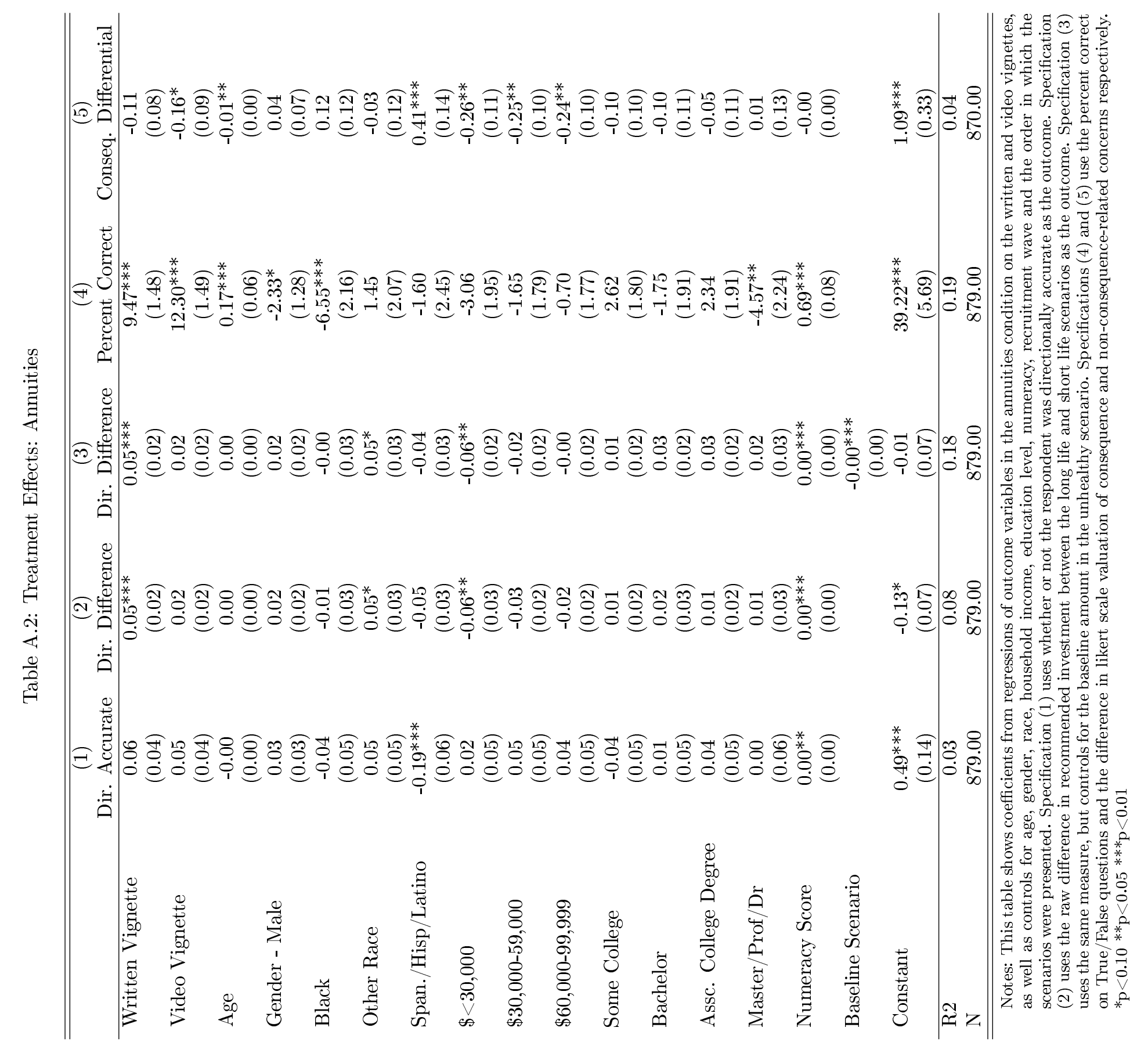




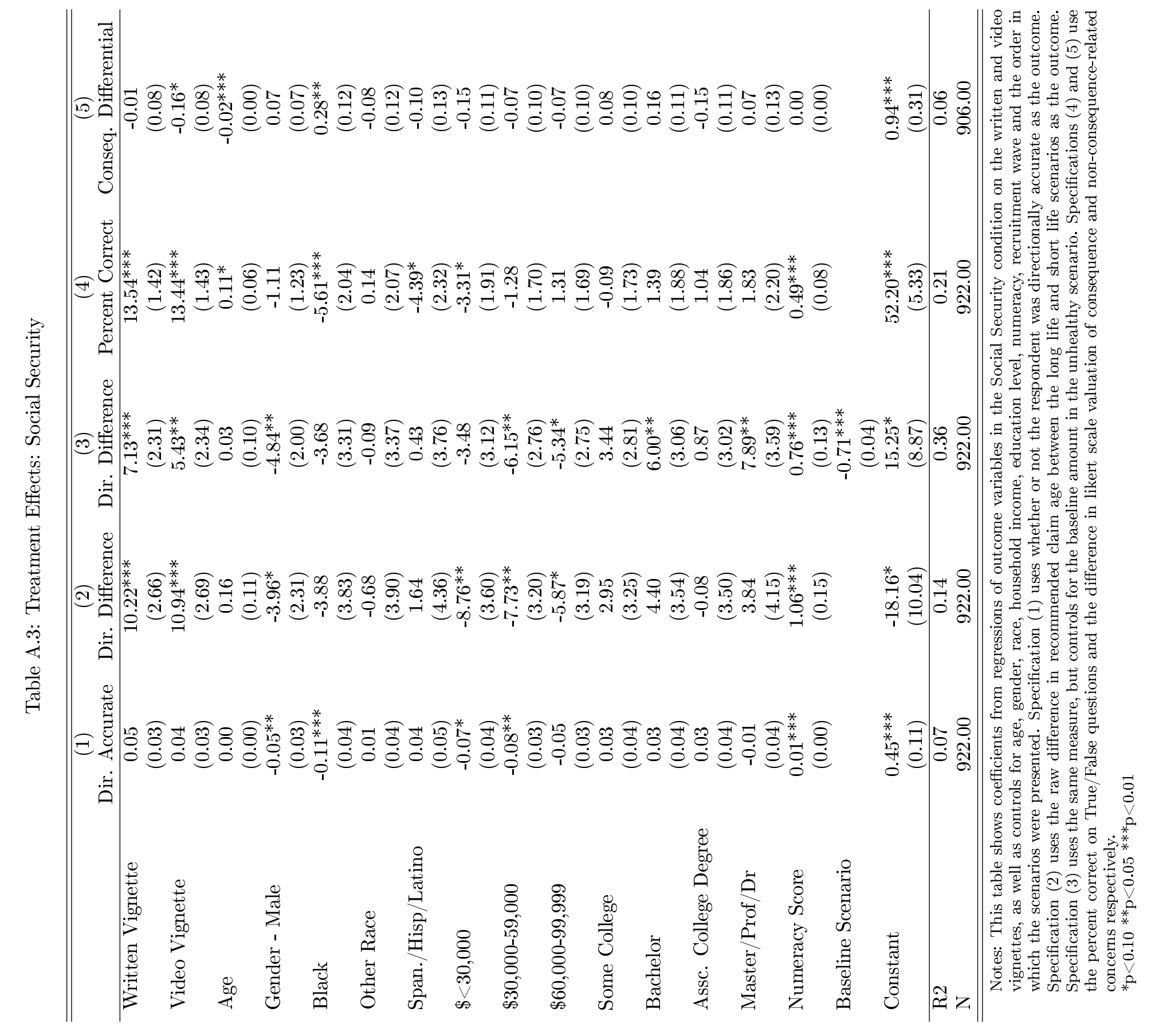




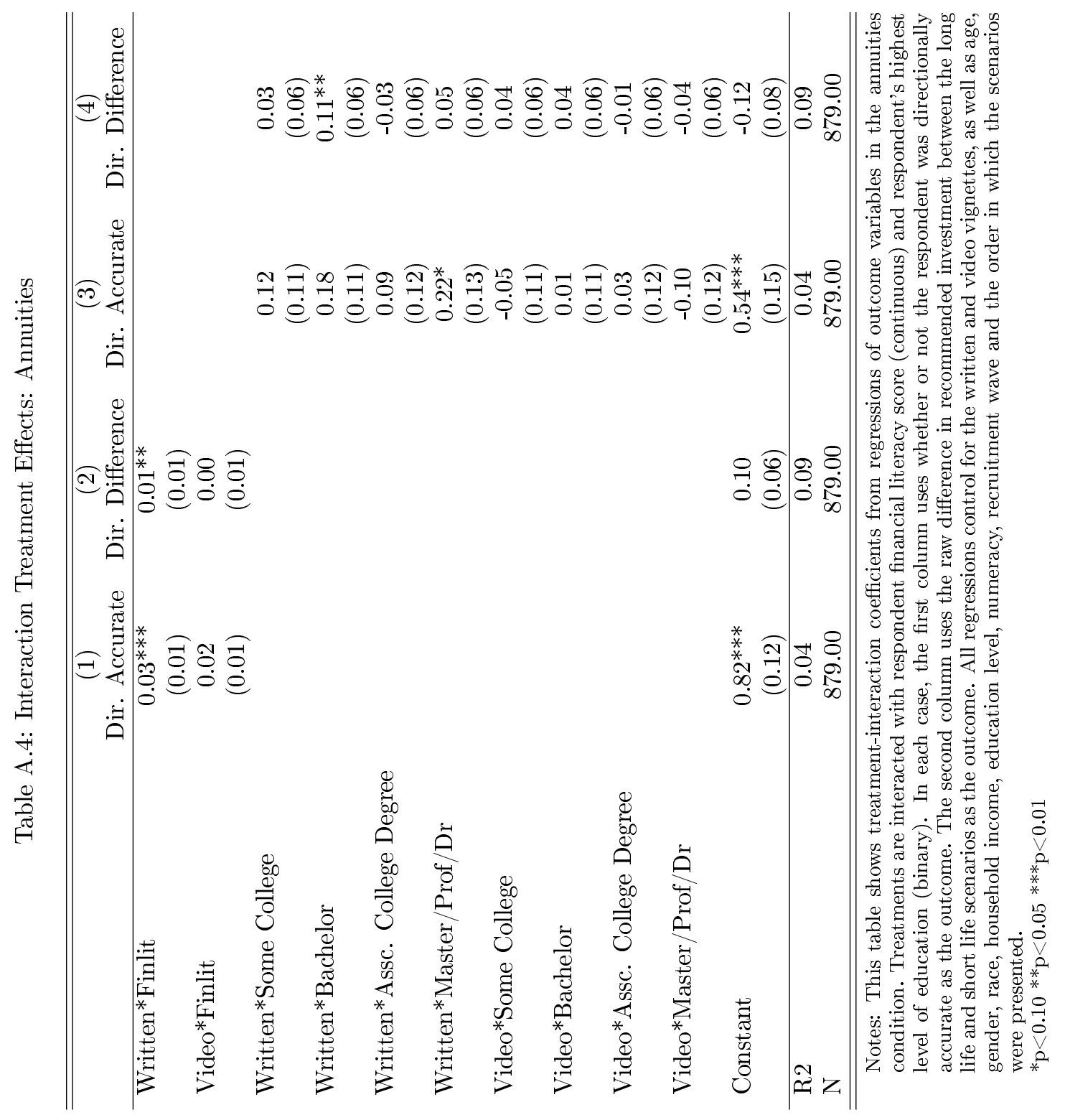




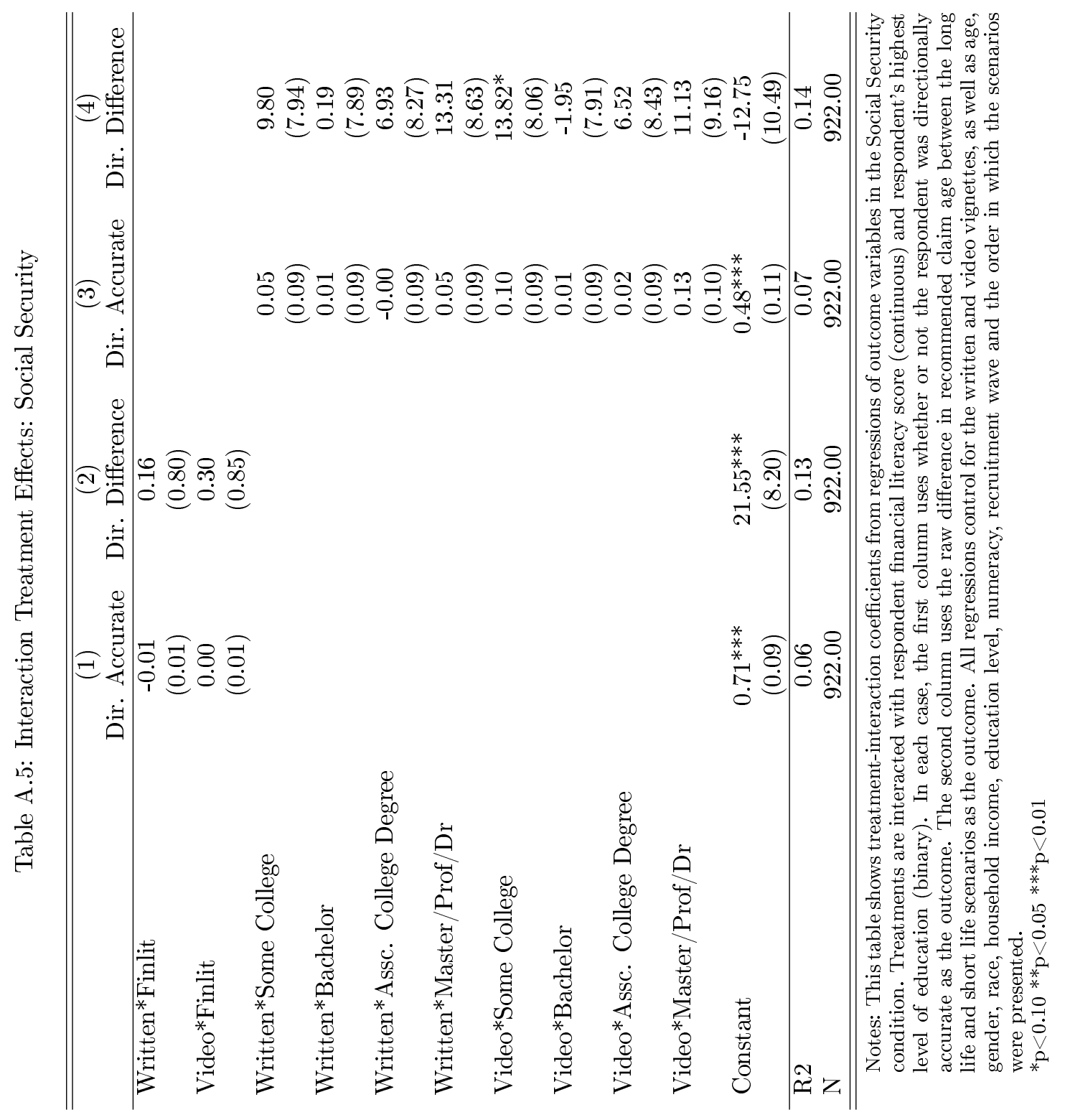




\section{Appendix B}

\section{Figure B1: Screenshots of Video Vignettes}

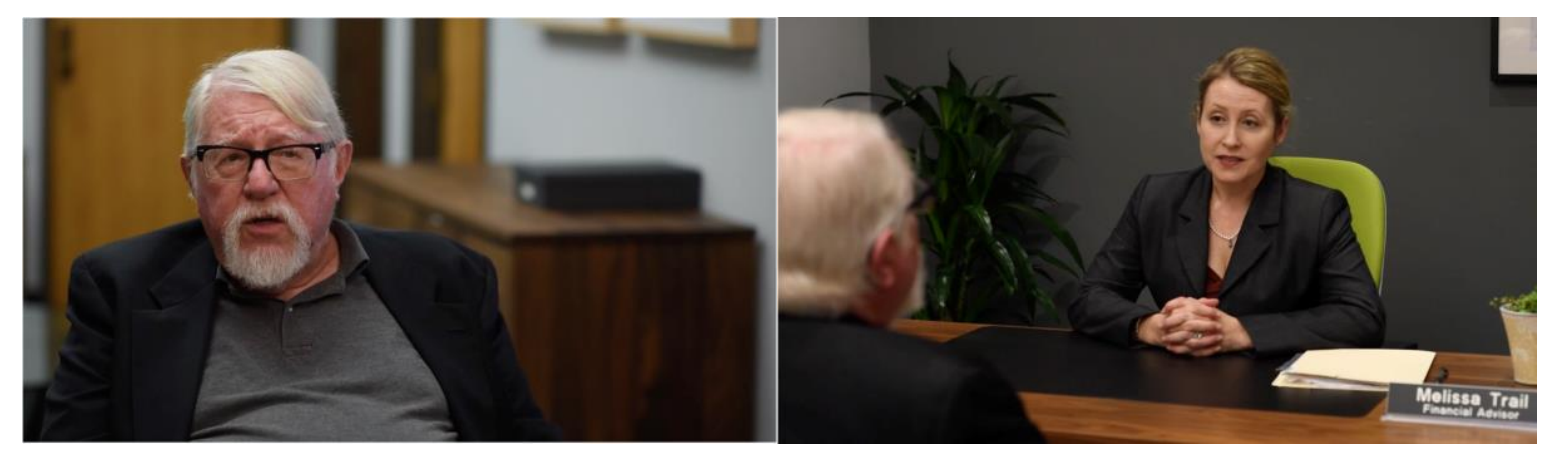

\section{Script B1: Annuities Written Script}

(Link B1: Annuities Vignette: https://www.youtube.com/watch?v=-AbXiHpXewU )

Bill is talking to his financial advisor in an office about how to spend down his savings in retirement.

Financial advisor: Good to see you today. How can I help?

Bill: Well, I've just retired recently and started claiming my Social Security benefits, and now I need to figure out how to budget my retirement savings.

Financial advisor: As a financial advisor, I can help you with that. It's a tradeoff. You can decide to spend down your retirement savings relatively quickly. In that case, you'll be more likely to enjoy your money while you're alive. But you also run the risk of having to cut back on your spending.

Bill: So, if I start spending relatively quickly and take all those vacation trips I've been wanting to, then I run the risk of not having the money when I need it?

Financial advisor: That's right. You could also decide to spend down your savings relatively slowly. In that case, you'll be less likely to run out of money. But then you run the risk of not getting to enjoy all of your money while you're alive.

Financial advisor: According to data from Social Security calculators, a man turning age 62 today can expect to live, on average, until he's 82 years old. That's about 20 years.

Financial advisor: The issue is, of course, we can't know now whether you'll live until 82 or beyond - these are just averages. 
Financial advisor: For example, if you think you'll only live until you're 80, you could spend each more money each month, but then you would have to cut back on your spending if you live past 80 .

Bill: But if I don't live to 80 , I may not be able to enjoy all my savings.

Financial advisor: Or if you think you'll live until you're 90, you should spend less each month, but again you'll still have to cut back on your spending if you live past 90 .

Bill: These are difficult decisions.

Financial advisor: The good news is that there are financial products that can help you reduce the risk of running out of money during your lifetime. One thing I can suggest is an annuity.

Bill: Ugh, annuities! I've heard that annuities are so complicated, and if you die early, basically you're throwing your money away.

Financial advisor: That's not entirely true. Annuities are like insurance against outliving your money. You pay a premium up front, but then you're guaranteed a monthly payment until you die. That means if you live longer, you also get to spend more money.

Bill: That's not such a bad deal ... so I make a payment now, and in return, I get a stream of income for life?

Financial advisor: Research shows that many people should consider annuitizing, but very few actually do. That's probably because of the misinformation floating around about annuities.

Bill: But if I buy an annuity, and I don't live as long as I expected, I still run the risk of not having a chance to spend most of my money before I die.

Financial advisor: That's true. But you do not have to annuitize all of your savings. You could annuitize half or even a quarter.

Bill: Ah, that's interesting. I'll think about it.

Financial advisor: Great, let's talk again soon.

\section{Script B2: Social Security Written Script}


(Link B2: Social Security Vignette: https://www.youtube.com/watch?v=pyOi27efL4Q )

Bill is talking to his financial advisor in an office about when to claim Social Security.

Financial advisor: Good to see you today. How can I help?

Bill: Well, I've been thinking about retiring soon, and I'm wondering what's the best time to actually claim my Social Security benefits.

Financial advisor: As a financial advisor, I can help you with that. Your retirement benefits depend on the age when you begin claiming. It's a tradeoff: you can decide to claim earlier. In that case, you would have lower monthly benefits, but you'd also get to enjoy these benefits for a longer period.

Bill: So if I claim sooner, I get less money per month?

Financial advisor: That's right. You can also decide to claim later. In that case, you would get higher monthly benefits, but you'd get to enjoy these benefits for a shorter period.

Bill: So I get more money per month, but I don't get to enjoy it for as long a time. These are hard decisions.

Financial advisor: According to data from Social Security calculators, a man turning age 62 today can expect to live, on average, until he is 82 years old. That's about 20 years!

Financial advisor: The issue is, of course, we can't know now whether you'll live until 82 or beyond - these are just averages.

Financial advisor: For example, if you think you'll only live until you are 80, you could claim sooner so you could enjoy these benefits for a longer period of time.

Bill: But the monthly payments will be lower.

Financial advisor: That's right. Or if you think you'll live until you are 90, you may want to delay claiming so you could get higher monthly payments.

Bill: So, the benefits will be higher, but I don't get to collect them for as long. These are hard decisions.

Financial advisor: Let me tell you more. You can claim any time after age 62. But for every year you delay, your benefits are increased by 5 to $8 \%$ each year. 
In this example, suppose you want to claim at age 62 - the earliest you could claim - your monthly benefit would be $\$ 750$ a month. Or if you delay until 63, your benefits go up to $\$ 800$ a month. Your benefits continue to increase each year until you get to your maximum monthly benefit of $\$ 1,320$ at age 70 . You can still claim after that, but your benefits won't increase.

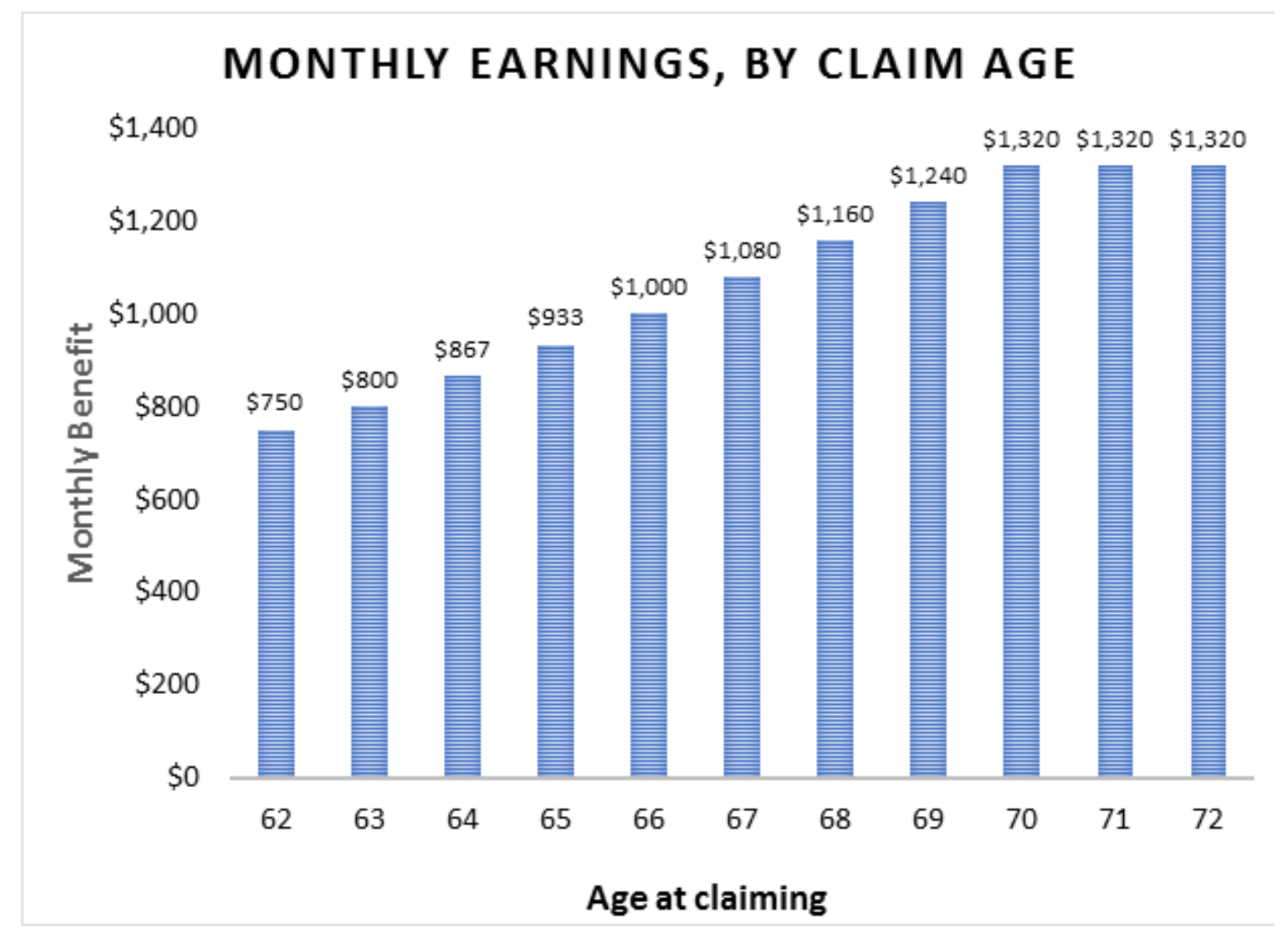

This is just an example based on retirement planning calculators available on ssa.gov and your earnings may differ. View your Social Security statement or visit ssa.gov to learn about your own benefits.

Bill: I understand that if I delay claiming I can get more money per month, but what if I just want to retire now. I'm so tired of working, and I just want to enjoy my life.

Financial advisor: A little known fact is you do not have to start claiming the same year you retire. You can retire, live off your retirement savings, and claim later if you want to. 
Financial advisor: For most people who have any retirement savings at all, delaying claiming could make sense for them because the amount of interest you earn on your retirement savings is lower than the amount of interest you get from Social Security just by postponing claiming.

Bill: Huh, I didn't know that. I'll think about it.

Financial advisor: Great, let's talk again soon.

\section{Appendix C}

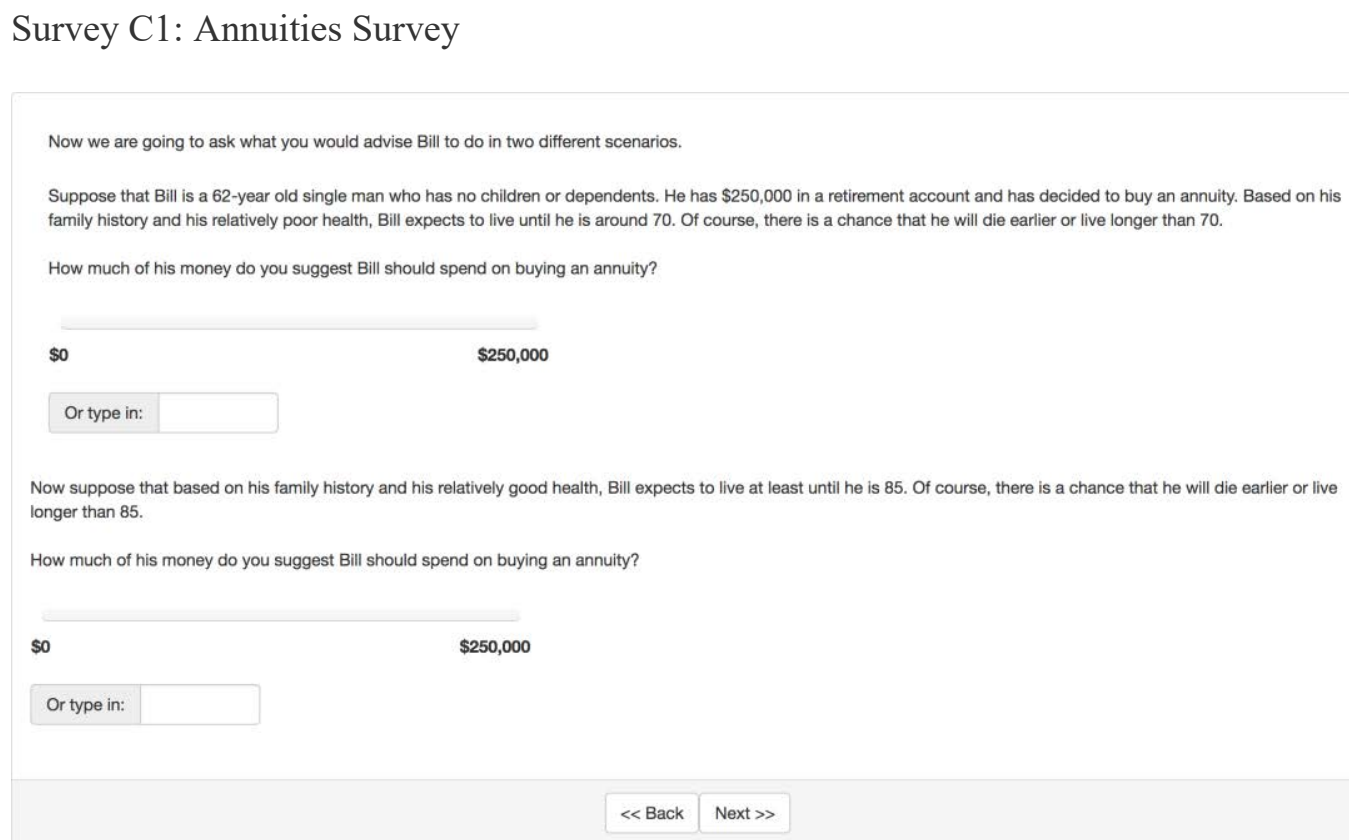

Do you think the following statements are true or false?

\begin{tabular}{|l|l|}
\hline & True \\
\hline You can buy an annuity with your retirement savings. \\
\hline An annuity is a financial product that pays a lump sum when you die. \\
\hline $\begin{array}{l}\text { An annuity is a financial product that is like insurance against outliving your money } \\
\text { in your lifetime. }\end{array}$ \\
\hline If you purchase an annuity, you can do so with just part and not all of your savings. \\
\hline
\end{tabular}


Please indicate how important you consider each of the below when planning for retirement:

\begin{tabular}{|l|l|l|l|l|l|}
\hline & $\begin{array}{c}\text { Not at all } \\
\text { Important }\end{array}$ & $\begin{array}{c}\text { Slightly } \\
\text { Important }\end{array}$ & Important & $\begin{array}{c}\text { Fairly } \\
\text { Important }\end{array}$ & $\begin{array}{l}\text { Nory Opinion } \\
\text { Important }\end{array}$ \\
\hline $\begin{array}{l}\text { The risk of not getting to spend most of your money in your } \\
\text { lifetime. }\end{array}$ & & & \\
\hline Whether you have enough money saved up for retirement. & & & \\
\hline The risk of running out of money in your lifetime. & & & \\
\hline Leaving money for your children or other dependents. & & \\
\hline Uncertainty about how long you will live.
\end{tabular}

« Back Next $\gg$

Suppose you want to learn more about annuities and have an option from one of the below. Which would you prefer to do?

Watch a video online (on your computer, phone or tablet)

Receive information in the mail

Read an article online (on your computer, phone or tablet)

None of the above

$\ll$ Back Next $\gg$

How likely are you to purchase an annuity in the future?

Extremely Unlikely

Unlikely

Neutral

Likely

Extremely Likely

You just read a story about annuities.

Can you comment on what you found most helpful about the story?

«Back Next $\gg$ 
Could you tell us how interesting or uninteresting you found the questions in this interview?
Very interesting
Interesting
Neither interesting nor uninteresting
Uninteresting
Very uninteresting

\section{$\ll$ Back Next $\gg$}

Do you have any other comments on the interview? Please type these in the box below.(If you have no comments, please click next to complete this survey.)

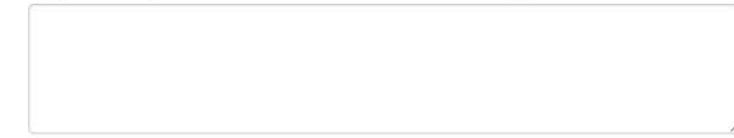

$$
\ll \text { Back Next } \gg
$$

\section{Survey C2: Social Security Survey}

\section{Now we are going to ask what you would advise John to do in two different scenarios.}

Suppose that John is a 62-year old single man who has no children or dependents. Based on his family history and his relatively poor health, John expects to live until he is around 70 . Of course, there is a chance that he will die earlier or live longer than 70 . Regardless of when he claims Social Security, John has enough retirement savings to live another 10 years before running out of money.

At what age do you suggest John should claim Social Security?

$\begin{array}{lllll}62 & 64 & 66 & 68 & 70\end{array}$

Now suppose that based on his family history and his relatively good health, John expects to live at least until he is 85 . Of course, there is a chance that he will die earlier or live longer than 85 . Regardless of when he claims Social Security, as before, John has enough retirement savings to live another 10 years before running out of money.

At what age do you suggest John should claim Social Security?

$\begin{array}{lllll}62 & 64 & 66 & 68 & 70\end{array}$

$$
\begin{array}{l|l}
\ll \text { Back } & \text { Next } \gg
\end{array}
$$

Do you think the following statements are true or false?

\begin{tabular}{|l|l|l|}
\hline & True & \\
\hline
\end{tabular}

$$
\text { « Back Next > }
$$


Please indicate how important you consider each of the below when planning for retirement:

\begin{tabular}{|l|l|l|l|l|l|}
\hline & $\begin{array}{c}\text { Not at all } \\
\text { Important }\end{array}$ & $\begin{array}{c}\text { Slightly } \\
\text { Important }\end{array}$ & $\begin{array}{c}\text { Important } \\
\text { Important }\end{array}$ & $\begin{array}{c}\text { No Opinion } \\
\text { Important }\end{array}$ \\
\hline $\begin{array}{l}\text { The risk of claiming Social Security too late and not getting to } \\
\text { enjoy the full benefits in your lifetime. }\end{array}$ & & & \\
\hline Uncertainty about how long you will live. & & & \\
\hline Leaving money for your children or other dependents. & & \\
\hline Whether you have enough money saved up for retirement. & < Back & Next $~$ & \\
\hline $\begin{array}{l}\text { The risk of claiming Social Security too early and getting a lower } \\
\text { monthly payment during your lifetime. }\end{array}$ & \\
\hline
\end{tabular}

Suppose you want to learn more about Social Security and have an option from one of the below. Which would you prefer to do?

Receive information in the mail

Watch a video online (on your computer, phone or tablet)

Read an article online (on your computer, phone or tablet)

None of the above

« Back Next $\gg$

Do you expect to be eligible for Social Security in the future?

Yes

No

Don't know

At what age would you choose to start claiming Social Security benefits?

Age in Years:

«<Back Next 》>

You just watched a video about Social Security benefits.

Can you comment on what you found most helpful about the video?

«<Back Next »> 


\section{Could you tell us how interesting or uninteresting you found the questions in this interview?}

Very interesting

Interesting

Neither interesting nor uninteresting

Uninteresting

Very uninteresting

$$
\text { «<Back Next > }
$$

Do you have any other comments on the interview? Please type these in the box below.(If you have no comments, please click next to complete this survey.)

«Back Next $\gg$ 